Western University Scholarship@Western

1997

\title{
On the Distributional Effects of Social Security Reform
}

\author{
Mark Huggett
}

Gustavo Ventura

Follow this and additional works at: https://ir.lib.uwo.ca/economicsresrpt Part of the Economics Commons

\section{Citation of this paper:}

Huggett, Mark, Gustavo Ventura. "On the Distributional Effects of Social Security Reform." Department of Economics Research Reports, 9710. London, ON: Department of Economics, University of Western Ontario (1997). 
ISSN:0318-725X

ISBN:0-7714-2025-0

\section{RESEARCH REPORT 9710}

On the Distributional Effects of Social

Security Reform

by

ECOHGAMCS REFEREHCE C:

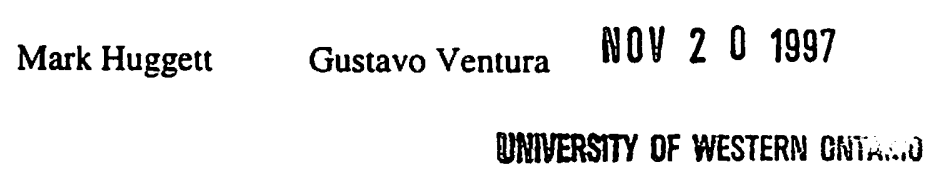

November 1997

Department of Economics Social Science Centre

University of Western Ontario

London, Ontario, Canada

N6A 5C2

econref@sscl.uwo.ca 


\title{
On the Distributional Effects of Social Security Reform
}

\author{
Mark Huggett Gustavo Ventura*
}

\begin{abstract}
How will the distribution of welfare. consumption and leisure across households be affected by social security reform? This paper answers this question for a social security reform with a two-tier structure by comparing steady states under a realistic version of the current US system and under the two-tier system. The first tier is a mandatory, defined-contribution pension offering a retirement annuity proportional to the value of taxes paid. whereas the second tier guarantees a minimum retirement income. Our findings do not in general favor the implementation of pay-as-rou go versions of the two-tier system for the US. The main findings are summarized in the introduction.
\end{abstract}

\footnotetext{
"Address of the authors:

Centro de Investigacion Economica- ITA.M. Av. Camino Sta. Teresa 930. Mexico D.F. 10700. Mexico. E-mail: huggert omaster.ster.itam.mx. Fax: 525 - 6284058.

Economics Department. University of Western Ontario. London. Ontario N6A 5C2. Canada. E-mail: gustaro öscyłla.ssci.uro.ca. Fax: 519 - 6613666.

We thank thank Selo Imrohoroglu for detailed comments. We also thank seminar participants at the 1997 . Neetings of the Societry for Economic Dynamics. the 1997 Latin American Meeting of the Econometric Society" and the 1997 Conference on "Drnamic Models of Policy Analysis".
} 


\section{Introduction}

"I urge all Americans to reflect on the significance of the Social Security .tct signed 50 years ago and to celebrate its accomplishments." - Ronald Reagan ${ }^{1}$

Although celebrations have been somewhat rare among young Americans. many people have in recent years joined Ronald Reagan in reflecting on the significance of the US social security system. Much of the reflection has been prompted by concerns over the future solvency of the system. The basic issue is that changing demographics as well as the expansion of social security benefits in past decades is projected to cause future social security tax rates to increase substantially if current health and retirement income benefit formulas remain unchanged. ${ }^{2}$

Concerns over solvency have coincided with proposals for fundamental social security reform. These proposals attempt to address the issues of equity and efficiency in addition to the solvency issue. A key question to ask of these reform proposals is the following: What are, in quantitative terms, the distributional effects of social security reform? We focus on distributional effects for three main reasons. First, distributional effects are potentially quite large given the size and scope of the US social security system. Second. exactly who wins and who loses from a proposed reform is key for determining whether a particular proposal will potentially be adopted. Finally; a careful investigation of distributional effects is required. as such effects are not summarized by a present value calculation of benefits received and taxes paid. This is because social security systems distort labor decisions and potentially change insurance possibilities in addition to redistributing income across households.

This paper investigates social security reforms with a two-tier structure. The first tier is a mandatory defined contribution pension scheme. whereas the second tier guarantees a minimum "floor" income in retirement to those whose social security pensions would otherwise fall below this floor level. Social security reforms with these properties have recently been advocated by the World Bank (see World Bank (1994)) and have been implemented in

\footnotetext{
${ }^{1}$ Social Security- Bulletin (1985. vol. 48. p. j)

${ }^{2}$ See Steurle and Bakija (1994. Ch. 3) for a review of these projections.
} 
a number of Latin American countries. ${ }^{3}$ Thus. our analysis of the replacement of the US system with a two-tier system should also be of interest to economists whose focus is not the US economy.

A reform plan with the attributes outlined above has been advocated for the LS by Michael Boskin. Consequently, from now on we will refer to a reform with these characteristics as a particular implementation of the "Boskin Proposal". Boskin (1986. p.19) summarizes the core features of his proposal as follows:

"The core of my proposal is to separate our national retirement policiesprimarily Social Security. Medicare, and their related programs-into two distinct parts. One part- sometimes called the annuity or insurance part- would provide actuarily equivalent insurance (i.e. identical returns to each dollar of taxes paid by everyone) for disability, catastrophic hospital care, and survivors and retirement annuities. The other- sometimes referred to as the welfare or the transfer part- would guarantee a minimally adequate level of retirement income for all citizens."

The "annuity" portion of benefits just described is to be financed either on a pay-as-you-go basis or on a fully-funded basis from proportional taxes on labor earnings. The "transfer" portion of benefits, which we subsequently call the floor benefit, is to be financed out of general revenues.

There are a number of distinct ways in which alternative social security systems. such as the Boskin proposal, can have economic effects. In particular. there can be redistributional. distortionary and insurance effects. Redistributional effects arise from redistributing income within and across generations. The L'S social security system redistributes income across generations via the use of pay-as-you-go financing and redistributes income within generations as benefits are not proportional to taxes paid. Redistribution across generations can have potentially large effects on the capital stock within lifecycle models. Distortionary effects can arise. even under complete markets. when the present value of marginal benefits received does not equal the value of marginal taxes paid. Since old-age benefits in the US are a concave function of an average of past earnings, the marginal benefit to an additional unit of taxes paid will differ widely even amoung households within the same age

\footnotetext{
${ }^{3}$ Chile. Colombia. Mexico and Peru all have systems with these features. See Cerda and Grandolini (1997) and Vorld Bank (1994).
} 
group. ${ }^{4}$ The literature on social security has emphasized the impact of these distortions on labor decisions. ${ }^{5}$ Insurance effects can arise. in the presence of incomplete markets. in a number of ways. We mention one of these that arises in our analysis. When there is random variation in an individual's labor productivity that is not insured. then an old-age benefit that is not proportional to social security tax payments could effectively provide partial insurance.

To analyze the distributional effects of implementing the Boskin proposal in place of current US arrangements we adopt a life-cycle framework. The particular model we use is rich enough to analyze the redistributional, distortionary and insurance effects discussed above. ${ }^{6}$ In particular. the model allows agents to make labor-leisure decisions. This is important in order to capture the distortionary effects of social security systems. In addition. the model allows agents to differ within an age group in ability levels. This permits a rich analysis of distributional effects within age groups. Within this framework distributional effects can be analyzed during the transition period as well as after the transition is over. We believe that both types of analysis are important. However, we choose to abstract from transition in order to focus with higher resolution on the distributional effects after the transition is over. ${ }^{7}$

The main results of the paper are summarized below and arise from steady-state comparisions of the US system and the Boskin proposal each under pay-as-you-go financing. ${ }^{8}$

\footnotetext{
${ }^{4}$ See Hurd and Shoven (1983) for calculations of differential returns to one and twoearner households in the US social security st'stem.

${ }^{5}$ See Aaron (1982) and Thompson (1083) for a review of this literature.

${ }^{6}$ The model we use is quite similar to that used by Huggett (1996) and by Huggett and Ventura (1997) to study the distribution of wealth and the distribution of savings in the US economy: These models build upon the work of Auerbach and Kotlikoff (1087). Hubbard and Judd (1987) and Imrohoroglu et al (1995).

'Kotlikoff (1996) and Huang. Imrohoroglu and Sargent (1997) analyze transitional effects of changes in social security: In Kotlikoff (1996) agents are identical within a generation and there is a labor-leisure choice. In Huang, Imrohoroglu and Sargent (1997) agents are heterogenous within a generation. but there is no labor-leisure choice. Heterogeneity within a generation and a labor-leisure choice are both essential in our analysis.

${ }^{8}$ An alternative would be to analyze the Boskin proposal under fully-funded financing. This is more difficult to analyze as transitions would need to be considered to determine the debt-GDP ratio in the new steady state. Additional debt arises from converting government social security obligations into debt.
} 
(1) The steady-state values of aggregate capital. labor. output and consumption under the $i$ S system are quite similar to those under versions of the Boskin proposal with the same social security tax rate. Thus if the Boskin proposal is to improve welfare for agents at all ability levels it must arise from a superior allocation of consumption and labor either over the life cycle or across states of nature.

(2) When the floor benefit is set to zero, high ability agents have a welfare gain worth a $10-15 \%$ increase in consumption each period and low ability agents have a welfare loss worth a $15-35 \%$ decrease in consumption. As the floor benefit increases both high and low ability agents can gain relative to the US system but median ability agents experience a welfare loss. By one steady-state welfare measure that attaches equal weight to the utility of all agents at birth, the aggregate gains derived from implementing the Boskin proposal are never positive.

(3) When only the old-age part of the US system is replaced by a twotier system. holding health and medical transfers constant across both systems, the results are qualitatively the same, even though the magnitudes of welfare gains and losses are smaller. Thus, high and low ability agents can still gain but median ability agents experience a welfare loss. Unlike the situation described in (2), aggregate welfare gains are positive (but relatively small) for one value of the floor benefit.

(4) Under the Boskin proposal with a low floor benefit. average hours worked are more than $5 \%$ higher early in life. This is because benefits are proportional to the total future value of taxes paid at the time of retirement whereas under the $[$ 'S system the old-age benefit depends on average indexed earnings and not on the timing of these earnings. As the floor benefit is increased the labor supply of low ability agents decreases significantly.

The paper is organized in five sections. Section 2 describes the model economies and the social security systems we analyze. Section 3 describes how parameters are set in the model economies. Section 4 presents the results. Section 5 concludes. 


\section{Model Economies}

In what follows we describe two different model economies that are identical in the structure of preferences. endowments and technology but differ in the nature of the social security arrangement employed.

\subsection{Environment}

We consider an overlapping generations economy. Each period a continuum of agents are born. Agents live a maximum of $N$ periods. The population grows at a constant rate $n$. All agents face a probability $s_{j}$ of surviving up to age $\mathrm{j}$ conditional on surviving up to age $\mathrm{j}-1$. These demographic patterns are stable so that age $j$ agents make up a fraction $\mu_{j}$ of the population at any point in time. ${ }^{?}$

All agents have identical preferences over consumption and labor and these are given by the following utility function:

$$
E\left[\sum_{j=1}^{N} \beta^{j}\left(\prod_{i=1}^{j} s_{i}\right) u\left(c_{j}, 1-l_{j}\right)\right]
$$

The period utility function $u(c, 1-l)$ is of the constant relative riskaversion class and is compatible with our focus on steady states.

$$
u(c .1-l)=\frac{\left[c^{\nu}(1-l)^{1-\nu}\right]^{(1-\sigma)}}{(1-\sigma)}
$$

Each agent is endowed with 1 unit of labor time each period. The value of an agent's period labor endowment in efficiency units is $e(z, j)$, which depends on age $j$ and an idiosyncratic shock $z$. The shock $z$ lies in a set $Z$ and follows a Mlarkov process. Labor productivity shocks are independent across agents. This implies that there is no uncertainty over the aggregate labor endowment even though there is uncertainty at the individual agent level. The function $e(z, j)$ is described in detail in section 3 .

At any time period $t$ there is a constant returns to scale production technology that converts capital $K$ and labor $L$ into output $Y$. The technology improves over time because of labor augmenting technological change. The

\footnotetext{
${ }^{9}$ The weights $\mu_{;}$are normalized to sum to 1 . where $\mu_{j-1}=\left(s_{j+1} /(1+n)\right) \mu_{j}$.
} 
technology level $A_{t}$ grows at a constant rate. $A_{t+1}=(1+g) A_{t}$. Each period capital depreciates at rate $\delta$.

$$
Y_{t}=F\left(K_{t}, L_{t} A_{t}\right)=A K_{t}^{\alpha}\left(L_{t} A_{t}\right)^{1-\alpha}
$$

\subsection{An Agent's Decision Problem}

The decision problem of an agent under each of the two social security arrangements that we consider can be described by specifying the following elements $\left(x, y, u(x, j, y), \Gamma(x, j), G\left(x, j, y, z^{\prime}\right)\right)$ :

$(x, j)$ state variables

$y$ control variables

$u(x, j, y)$ period utility of an age $j$ agent in state $x$ using control $y$.

$\Gamma(x, j)$ current period budget set as a function of the state $(x, j)$.

$G\left(x, j, y, z^{\prime}\right)$ law of motion determining next period's state $x^{\prime}$ as a function of the state $x$. age $j$, control $y$ and the shock $z^{\prime}$ the agent receives next period.

The decision problem of an agent can then be expressed (after some convenient transformations that will be discussed shortly) for each social security system that we consider as the following dynamic programming problem. In the problem below the value function is set equal to zero after the last period of life. $V(x, \nu+1)=0$.

$$
V(x, j)=\max _{(y)} u(x, j, y)+\beta(1+g)^{\nu(1-\sigma)} s_{j+1} E\left[V\left(x^{\prime}, j+1\right) \mid x\right]
$$

subject to $y \in \Gamma(x, j)$ and $x^{\prime}=G\left(x, j, y, z^{\prime}\right)$ 


\subsubsection{Social Security System 1: US System}

States and Controis: $x=(a . \bar{e} . z), y=\left(l, a^{\prime}\right)$

Budget Set:

$$
\begin{aligned}
& \Gamma(x, j)=\left\{\left(l, a^{\prime}\right): c \geq 0, a^{\prime} \geq 0, l \in[0,1] ;\right. \\
& \left.c+a^{\prime}(1+g) \leq a(1+r(1-\tau))+(1-\tau-\theta) l e(z, j) w+b(x, j)\right\}
\end{aligned}
$$

Law of Motion:

$$
\begin{aligned}
& G\left(x, j, y, z^{\prime}\right)=\left(a^{\prime}, \bar{e}^{\prime}, z^{\prime}\right) \\
& \bar{e}^{\prime}= \begin{cases}{\left[\bar{e}(j-1)+\min \left\{w e(z, j) l, e_{\max }\right\}\right] / j} & j<R \\
\bar{e} & j \geq R\end{cases}
\end{aligned}
$$

In the model economies where social security benefits are determined by the US System an individual agent's state variable is $x=(a, \bar{e}, z)$. The state $x=(a, \vec{e}, z)$ of an age $j$ agent describes the agent's asset holdings $a$. average past earnings $\bar{e}$ and idiosyncratic shock $z$. The state determines the current period budget set $\Gamma(x, j)$. The budget set specifies that consumption $c$ plus assets $a^{\prime}$ carried over to next period are no greater than current period resources. These resources come from labor earnings $e(z, j) w l$. the value of current period assets $a(1+r)$ and a social security benefit $b(x, j)$. Agents face a common real wage $w$ per efficiency unit of labor and a real interest rate $r$ on asset holdings. There is an income $\operatorname{tax} \tau$ as well as a social security $\operatorname{tax} \theta$ on labor earnings. The period utility $u(x, j, y)$ is obtained from the underlying utility function $u(c .1-l)$ after substituting out consumption using the current period budget set. The budget set also imposes the restriction that agents face a borrowing constraint in that net asset holdings $a^{\prime}$ cannot be negative.

Social security benefits $b(x, j)$ are allowed to depend on age $j$ as well as the state $x$, although benefits will depend on the state $x$ only through the level of average past earnings $\bar{e}$. This formulation is capable of capturing a number of features of the L'S social security system such as the fact that benefits are paid out as an annuity after a retirement: age $R$ and the fact that benefits are a concave function of average past earnings. Average past earnings $\bar{e}$ is calculated on an indexed basis so that average earnings in the economy are the same in all years after indexing. This is accomplished in the model 
economies by transforming the wage rate as described below. Note that the calculation of average earnings only credits earnings below some maximum level $e_{\max }$. This follows the way in which averaged indexed earnings are calculated in the US social security system.

In the above dynamic programming problem. we assume that the economy is in a constant growth equilibrium in which the real interest rate is constant and in which the real wage grows at the rate of technological progress. To facilitate the computation of equilibrium. we transform variables to eliminate the effects of growth. We transform individual asset holdings, consumption. social security benefits and wages by dividing by the technology level $\left(A_{t}\right)$. This transformation accounts for the unusual term $(1+g) a^{\prime}$ in the budget set as well as the term $(1+g)^{\nu(1-\sigma)}$ in the objective of the dynamic programming problem. To eliminate the effects of growth. we transform aggregate capital and labor inputs as well as government consumption by dividing by $A_{t} N_{t}$, where $N_{t}$ is the number of people in the economy.

\subsubsection{Social Security System 2: Boskin Proposal}

States and Controls: $x=\left(a_{1}, a_{2}, z\right), y=\left(l, a_{1}^{\prime}\right)$

Budget Set:

$$
\begin{aligned}
& \Gamma(x, j)=\left\{\left(l, a_{1}^{\prime}\right): c \geq 0, a_{1}^{\prime} \geq 0, l \in[0,1]\right. \\
& \left.c+a_{1}^{\prime}(1+g) \leq a_{1}(1+r(1-\tau))+\left(1-\tau-\theta_{j}\right) l e(z \cdot j) w+b(x, j)\right\}
\end{aligned}
$$

Law of Motion:

$$
\begin{aligned}
G\left(x, j, y, z^{\prime}\right) & =\left(a_{1}^{\prime}, a_{2}^{\prime}, z^{\prime}\right) \\
(1+g) a_{2}^{\prime} & = \begin{cases}\left(a_{2}+\theta l e(z, j) w\right)(1+r) & j<R \\
a_{2} & j \geq R\end{cases}
\end{aligned}
$$

Under the Boskin proposal the state variable $x=\left(a_{1}, a_{2}, z\right)$ accounts for privately held assets $a_{1}$, the shock $z$ as well as an accounting variable $a_{2}$ representing the accumulated value of social security taxes paid. At birth the accounting variable is set equal to zero. The period budget set is of the same form as under the US system described previously. The key difference lies in how social security benefits are related to taxes paid. The benefit function 
$b(x, j)$ specifies that benefits are paid out after a retirement age $R$. These benefits are given by an "annuity payment" $b\left(a_{2}, j\right)$, which is constant in real terms and is proportional to total taxes paid $a_{2}$ up to the retirement age, or a floor level $\underline{b}$ whichever is greater. ${ }^{10}$ As the floor will be set proportional to output per person in the economy it is possible that immediately after retirement the annuity component of benefits could be larger than the floor and that later on the opposite could be true. The social security tax rate $\theta_{j}$ is set equal to a constant value $\theta$ for agents below the retirement age and equal to zero above the retirement age.

$$
b(x, j)= \begin{cases}0 & j<R \\ \max \left\{\underline{b}, b\left(a_{2}, j\right)\right\} & j \geq R\end{cases}
$$

\subsection{Equilibrium}

The definition of equilibrium for either social security scheme under pay-asyou-go financing is given below. At a point in time agents are heterogeneous in their age $j$ and their individual state $x$. The distribution of individual states $x$ across age $j$ agents is represented by a probability measure $i_{j}$ defined on subsets of the individual state space $X$. So let $\left(X, B(X), \psi_{j}\right)$ be a probability space where $X=[0, \infty) \times[0, \infty) \times Z$ is the state space under both security systems and $B(X)$ is the Borel $\sigma$-algebra on $X$. Thus, for each set $B$ in $B(X), \psi_{j}(B)$ represents the fraction of age $j$ agents whose individual states lie in $B$ as a proportion of all age $j$ agents. These agents then make up a fraction $\mu_{j} \psi_{j}(B)$ of all agents in the economy: where $\mu_{j}$ is the fraction of age $j$ agents in the economy: The distribution of individual states across age $l$ agents is determined by the exogenous initial distribution of labor productivity shocks since all agents start out with no assets. The distribution of individual states across age $j=2.3 \ldots . . \mathrm{V}$ agents is then given recursively as follows:

$$
\dot{\psi}_{j+1}(B)=\int_{X} P(x, j, B) d w_{j}
$$

\footnotetext{
${ }^{10}$ In Boskin (1986. Ch. 8), the floor benefit is determined by an income means test. Our formulation differs as the floor benefit is independent of labor and asset income in retirement. However, the vast majority of agents receiving floor benefits in our model economies have essentially zero labor and asset income in retirement.
} 
The function $P(x, j, B)$ is a transition function which gives the probability that an age $j$ agent transits to the set $B$ next period. given that the agent"s current state is $x$. The transition function is determined by the optimal decision rule on asset holding and by the exogenous transition probabilities on the labor productivity shock $z .^{11}$

Definition: At steady-state equilibrium is $(c(x, j), a(x, j), l(x, j), w, r, K$, $\left.L, G, T, T R, \theta_{j}, b(x, j), \tau\right)$ and distributions $\left(\dot{\psi}_{1}, \ldots, \psi_{N}\right)$ such that

1. $c(x, j), a(x, j)$ and $l(x, j)$ solve the dynamic programming problem.

2. Competitive Input Markets: $w=F_{2}(K, L)$ and $r=F_{1}(K . L)-\delta$

3. Markets Clear:

(i) $\left.\sum_{j} \mu_{j} \int_{X}(c \mid x, j)+a(x . j)(1+g)\right) d v_{j}+G=F(K . L)+(1-\delta) K$

(ii) $\sum_{j} \mu_{j} \int_{X} a(x, j) d \dot{w}_{j}=(1+n) K$

(iii) $\sum_{j} \mu_{j} \int_{X} l(x, j) e(z, j) d \dot{w}_{j}=L$

4. Distributions are Consistent with Individual Behavior:

$$
\psi_{j+1}(B)=\int_{X} P(x, j, B) d \psi_{j} \text { for } j=1, \ldots, N-1 \text { for all } B \in B(X)
$$

5. The Government Budget Constraint is satisfied:

$G=\tau(r K+w L)+T-T R$

$T=\left[\sum_{j} \mu_{j}\left(1-s_{j+1}\right) \int_{X} a(x . j)(1+r(1-\tau)) d \psi_{j}\right] /(1+n)$

$T R=0$ for US System.

$T R=\sum_{j \geq R} \mu_{j} \int_{\left\{x: \underline{b}>b\left(a_{2} . j\right)\right\}}\left(\underline{b}-b\left(a_{2}, j\right)\right) d \dot{w}_{j}$ for Boskin Proposal

6. Social Security Budget Balance:

$w \sum_{j} \theta_{j} \mu_{j} \int_{X} l(x . j) e(z . j) d \dot{w}_{j}=\sum_{j \geq R} \mu_{j} \int_{X} b(x . j) d \dot{v}_{j}$ US System

$w \sum_{j} \theta_{j} \mu_{j} \int_{X} l(x . j) e(z . j) d \psi_{j}=\sum_{j \geq R} \mu_{j} \int_{X} b\left(a_{2}, j\right) d \dot{w}_{j}$ Boskin Proposal

In the above definition conditions 1-4 are fairly standard. Thus, we focus on the remaining two conditions. Condition 5 states that in each period government consumption $G$ equais income taxes plus the aggregate value of all accidental bequests $T$, which the government taxes fully, less the aggregate

\footnotetext{
${ }^{11}$ The transition function is $P(x, j, B)=\operatorname{Prob}\left(\left\{z^{\prime}:\left(a(x, j), \bar{e}^{\prime}, z^{\prime}\right) \in B\right\} \mid z\right)$ under the US system and $\left.P(x, j, B)=\operatorname{Prob}\left(\left\{z^{\prime}:(a, x, j), a_{2}^{\prime}, z^{\prime}\right) \in B\right\} \mid z\right)$ under the Boskin proposal. The relevant probability is the conditional probability that describes the behavior of the Markov process $z$.
} 
transfers $T R$ paid out. There are transfers $T R$ financed out of general revenues under the Boskin proposal but there are no such transfers under the LiS system. Transfers under the Boskin proposal equal the amount that social security annuity benefits fall below the floor benefit level when summed over the population. Condition 6 says that social security is financed on a payas-you-go basis with a payroll tax under both the US system and the Boskin proposal. Linder the Boskin proposal it is only the annuity component of benefits of current retirees that are financed with the payroll tax.

\section{Calibration}

In this section we explain how we select the parameters of the model economy: First. we specify preference, technology and demographic parameters. Second. we parameterize the labor endowment process. Lastly, we parameterize each social security system.

\subsection{Preferences, Technology and Demographics}

Table 1

Model Parameters

\begin{tabular}{cccccccccc}
\hline$\beta$ & $\sigma$ & $\nu$ & $A$ & $\alpha$ & $\delta$ & $g$ &. $\mathrm{~V}$ & $n$ & $s_{j}$ \\
\hline 1.011 & 2.0 & .33 & 0.895944 & .36 & .06 & .021 & 81 & .012 & US 1994 \\
\hline
\end{tabular}

The preference parameters $(3, \sigma . \nu)$ are set using a model period of one year. We follow the work of Rios-Rull (1996) in our settings of these parameters. The discount factor 3 is set equal to the estimate in Hurd (1989). This value of the discount factor together with declining values of the survival probability is capable of generating a hump-shaped profile of consumption over the life cycle. The parameters $(\sigma, \nu)$ determine the elasticity of intertemporal substitution of consumption. This elasticity is $(1 / 1-\nu(1-\sigma))$ and equals .75 for the parameter values listed in Table 1 . This is in the range of values estimated in the microeconomic studies reviewed in Auerbach and Kotlikoff (1987) and in Prescott (1986). ${ }^{12}$ In infinitely-lived agent models.

\footnotetext{
${ }^{12}$ See Rios-Rull (1996) for an analysis of the importance of this parameter in producing realistic capital-output ratios in life-cycle models.
} 
the leisure parameter $\nu$ is often set so that $1 / 3$ of discretionary time is devoted to market work in steady state. ${ }^{13}$ In life-cycle economies. there is no simple relationship between the leisure parameter $\nu$ and the fraction of time devoted to market work. However. we find. as does Rios-Rull (1996), that with the parameter values listed in Table 1 agents under age 65 devote on average $31-32$ percent their time to market work. This occurs even though market work varies with age over the life cycle.

The technology parameters $(A, \alpha, \delta, g)$ are set as follows. Capital's share of output $\alpha$ is set following the estimate in Prescott (1986). The technology level $A$ can be normalized freely so we set its value such that, whenever the capital to output ratio equals 3.0. the wage rate equals 1.0. Using $\alpha=0.36$. this choice implies the value for $A$ in Table 1 . The depreciation rate $\delta$ is set equal to the estimate in Stokey and Rebelo (1995). The rate of technological progress $g$ is set to match the average growth rate of GDP per capita from $1959-94 .{ }^{14}$

The demographic parameters $\left(N, s_{j}, n\right)$ are set using a model period of one year. Thus, agents are born at a real-life age of $20($ model period 1$)$ and live up to a maximum real-life age of 100 (model period 81). We set the population growth rate $n$ equal to the average US population growth rate 1959-94 as reported in the Statistical Abstract of the US (1995. Table 2 p. 8). The survival probabilities are set equal to the Social Security Administration's survival probabilities for men for the year $1994 .^{15}$

In the model economies we set government consumption equal to a fixed fraction of output. When government consumption is defined as federal. state and local government consumption then government consumption averaged 19.5 percent of output from 1959-94 according to the Survey of Current Business (1994. Table 1 and 1995. Table 1.1). Thus. we set $G / Y=.195$ in the model economies. The tax rate $\tau$ is set endogenously to cover these consumption expenditures after accounting for the revenue coming from estate taxation. Under the Boskin plan the tax rate is set so as to finance the same path of government consumption as under the US Social Security system. Of course, the tax rate is also set to pay for additional social security benefits for those agents whose annuity benefit is below the floor benefit level.

\footnotetext{
${ }^{13}$ Ghez and Becker (1975) and Juster and Stafford (1991) estimate this fraction.

${ }^{14}$ The GDP data is from the Survey of Current Business (1996. Table 2. p. 110). The population data is from the Statistical Abstract of the US (1995. Table 2. p. 8).

${ }^{15}$ We thank Jagadeesh Gohkale for providing us with this data.
} 


\subsection{Labor Endowments in Efficiency Units}

We consider a labor endowment process where the natural log of the labor endowment of an age $j$ agent in efficiency units $\left(y_{j}\right)$ regresses to the mean log endowment of age $j$ agents $\left(\bar{y}_{j}\right)$ at rate $\gamma$. This process as well as the labor endowment function $e(z, j)$ are as follows:

$$
\begin{aligned}
& y_{j}-\bar{y}_{j}=\Upsilon\left(y_{j-1}-\bar{y}_{j-1}\right)+\epsilon_{j}, \text { where } \epsilon \sim N\left(0, \sigma_{\epsilon}^{2}\right), y_{1} \sim N\left(\bar{y}_{1}, \sigma_{y_{1}}^{2}\right) \\
& e(z, j)=\exp ^{\left(z+\bar{y}_{j}\right)}, \text { where } z \equiv y_{j}-\bar{y}_{j}
\end{aligned}
$$

The parameters of the labor endowment process are set as follows. First. we set the profile of mean log endowment to match the ['S cross-sectional labor endowment efficiency profile estimated by Hansen (1993). ${ }^{16}$ This profile is given in Figure 1.

\section{[Insert Figure 1 Here]}

Second, we need to set values for the parameters $\left(\gamma, \sigma_{\epsilon}^{2}, \sigma_{y_{1}}^{2}\right)$. Since the wage rate $w^{\prime}$ per efficiency unit of labor is common to all agents. the labor endowment process is equivalent to an individual-specific wage process. This suggests setting these parameters using data on (i) the magnitude and persistence of individual-specific wage shocks and (ii) the concentration of wages. Unfortunately, we do not have data on the magnitude and persistence of shocks to log wages even though there are studies measuring the concentration of wages. Thus. we will consider indirect methods for setting these parameters.

We consider two specifications for the wage process. In the "no idiosyncratic shock" specification. agents are born with differences in ability levels that are perfectly preserved over their lives. Thus we set $\left({ }_{i}, \sigma_{\epsilon}^{2}\right)=(1.0 .0 .0)$. The remaining parameter. $\sigma_{y_{1}}^{2}$ is chosen so that the Gini coefficient of the wage distribution matches recent estimates of the Gini coefficient of wages in US cross-section data. In this regard. Ryscavage (1994) reports a wage Gini coefficient for all earners equal to 0.345 in 1989 . We therefore choose

\footnotetext{
${ }^{16}$ Hansen estimates median wage rates in cross-section data for males in different age groups. We use his values for the center of the age group and linearly interpolate to get the remaining values. We set the labor endowment in efficiency units of agents at a real-life age of 75 to zero.
} 
$\sigma_{y_{1}}^{2}=.376$ so that the wage Gini equals .35 for agents in our model economy under age $6 .^{17}$

In the "idiosyncratic shock" specification agents experience idiosyncratic shocks in each period of life. We use the following procedure to set parameter values. First. we set $\sigma_{y_{1}}^{2}=.27 .{ }^{18}$ Second, for alternative choices of $\sigma_{\epsilon}^{2}$, we select values for $\gamma$ that produce a wage Gini coefficient for agents under age 65 equal to .35. Finally, for each of these pairs $\left(\gamma, \sigma_{\epsilon}^{2}\right)$ we compute equilibria in model economies with the L.S. social security system and simulate earnings data from these economies. We use the artificial data created by the model economies to estimate by ordinary least squares the parameters of a regression to the mean process for earnings. We select the pair $\left(\gamma, \sigma_{\epsilon}^{2}\right)$ that replicates the value of the regression to the mean parameter estimated in the literature on labor earnings.

On the basis of this procedure we choose $\left(\gamma, \sigma_{\epsilon}^{2}\right)=(.985, .015)$. Table 2

Table 2: Estimates for the Earnings Process ${ }^{19}$

\begin{tabular}{|l|c|c|c|c|}
\hline wage & wage & earnings & earnings & \\
$\sigma_{\epsilon}^{2}$ & $\gamma$ & $\hat{\gamma}$ & $\hat{\sigma}_{\epsilon}^{2}$ & $R^{2}$ \\
\hline 0.010 & 0.992 & 0.9804 & 0.0659 & 0.8999 \\
& & $(0.0004)$ & & \\
0.015 & 0.985 & 0.9634 & 0.0868 & 0.8703 \\
& & $(0.00047)$ & & \\
0.020 & 0.978 & 0.9432 & 0.1116 & 0.8328 \\
& & $(0.00055)$ & & \\
\hline
\end{tabular}

shows that these values replicate the recent estimate of $y$ from Hubbard et al (1995). These authors report estimates for $\gamma$ equal to $.96 . .95$ and .96 for

\footnotetext{
${ }^{17}$ We approximate each wage model with a finite number of discrete values. The shock $z$ in each model takes on 21 evenly-spaced values between $-4 \sigma_{y_{1 / 1}}$ and $4 \sigma_{y_{1}}$. Transition probabilities are calculated by integrating the area under the normal distribution conditional on the value of $z$.

${ }^{18}$ We note that this choice implies that the earnings Gini coefficient of the voungest agents in the model economies equals .306. This is above the estimates reported by Shorrocks (1980), who reports a value of .268. We take this as a lower bound as households with zero earnings are excluded from the sample.

${ }^{19}$ The estimation of the parameters $\dot{\gamma}$ and $\tilde{\sigma}_{\epsilon}^{2}$ is done for agents 20-64 years old. Agents with zero earnings are excluded from the sample. Values in parenthesis correspond to standard errors.
} 
households with less than 12 years of education. 12-15 years of education and 16 or more years of education using annual earnings data from $1982-1986$.

\subsection{Social Security}

Under the US System. we set benefits as follows:

$$
b(x, j)= \begin{cases}0 & j<R \\ b+b(\bar{e}) /(1+g)^{j-R} & j \geq R\end{cases}
$$

In this specification benefits are paid begining at a retirement age $R=46$ (a real-life age of 65). At a point in time. all agents past the retirement age receive the common benefit $b$ in addition to an earnings-related benefit $b(\bar{e})$. The earnings-related benefit is paid out as a constant real annuity. As we transform variables by dividing by the technology level. the extra term $(1+g)^{j-R}$ appears in the denominator even though this component of benefits is constant in real terms for a given person after retirement.

We calibrate the common benefit $b$ based on the hospital and medical component of social security benefits. These benefits are paid to all qualifying members of the US social security system regardless of earnings history. Over the period 1990-94 the hospital and medical payment per retiree averaged 7.72 and 4.70 percent of GDP per person over age $20{ }^{20}$ Thus, the common benefit is set at $b=0.1242 Y$, where $Y$ is GDP per capita.

The earnings-related benefit is calibrated to the old-age social security benefit formula applicable in the same period. The relationship between average past earnings $(\bar{e})$ and old-age benefits in the model economy is given in Figure 2. As Figure 2 shows. the earnings-related component is a concave function of average past earnings.

[Insert Figure 2 Here]

We calculate the earnings-related benefit $b(\bar{e})$ as follows. In the US the old-age benefit is called the primary insurance amount (PIA). The PIA is related to a retiree's averaged indexed monthly earnings (AIME). In 1994 the PIA equaled 90 percent of the first $\$ 422$ of AIME. 32 percent of the

\footnotetext{
${ }^{20}$ Statistical Supplement of the Social Security Bulletin (1996. Tables 8.A.1 and 8.A.2) and Economic Report of the President (1996. Tables B1 and B30).
} 
next $\$ 2123$ of AIME and 15 percent of AIME over $\$ 2545$. The values at which these percentages change are called bend points. We calculate these bend points relative to average earnings in each year 1990-94. The bend points occured on average at .20 and 1.24 times average earnings. ${ }^{21}$ After amendments to Social Security legislation in 1977. bendpoints have been increased automatically in proportion to average earnings.

Recall that only earnings up to some maximum earnings level $e_{\max }$ are used in computing the variable average past earnings $\bar{e}$. Thus, we also need to set this parameter. As the maximum creditable earnings in the US social security system averaged 2.47 times average earnings over the period 1990-94, we set $e_{\max }$ equal to 2.47 times average earnings per person. ${ }^{22}$

Under the Boskin proposal benefits are determined by the greater amount of an annuity payment $b\left(a_{2}, j\right)$, which is constant in real terms and is proportional to the value of taxes paid $a_{2}$ up to the age of retirement, and a floor benefit $\underline{b}$ :

$$
b(x, j)= \begin{cases}0 & j<R \\ \max \left\{\underline{b}, b\left(a_{2}, j\right)\right\} & j \geq R\end{cases}
$$

We set the benefit parameters as follows. First, the age of receipt of retirement benefits $R$ as well as the social security tax rate $\theta$ are set equal to the values in the model economy with the US social security system. Second, a number of values for the floor benefit level varying from zero times ouput per person $(\underline{b}=.0 Y)$ to .35 times output per person $(\underline{b}=.35 Y)$ are considered. Third. the proportionality factor $C$ determining the annuity benefit must be set. where $b\left(a_{2}, j\right)=C a_{2} /(1+g)^{j-R}$. Given the transformation of variables. transformed benefits shrink for a given person over time at rate $g$ even though untransformed benefits are constant in real terms. The proportionality factor $C$ is then set so that benefit payments to current retirees equals current social security tax payments (condition 6 in the definition of equilibrium).

\section{Results}

Our results are presented in two subsections. We first present some general features of the model economies. We then analyze the distributional effects

\footnotetext{
${ }^{21}$ Social Security Bulletin (1993. 1994).

${ }^{22}$ Social Security Handbook (1995). Social Security Bulletin (1993. 1994).
} 
which are the focus of the paper. Details of how the results are computed are described in the Appendix.

\subsection{General Features}

Tables 3 and 4 below describe some general features of the model economies. Several points are worth noting here. First. for low retirement floor levels, aggregate capital $(K)$ and labor $(L)$ inputs under the US system are below those in the Boskin proposal. whereas for relatively high floor levels $(\underline{b}=.35 Y)$, the opposite pattern is true. However, we note that economic aggregates as well as factor prices do not differ dramatically across steady states. Intuitively, one reason for this is that the amount of intergenerational redistribution is similar in the US system and the versions of the Boskin proposal we study. Intergenerational redistribution is quite similar as social security tax rates are identical across steady states and as the financing of benefits is always on a pay-as-you-go basis.

Table 3: General Features -No Idiosyncratic Shocks

\begin{tabular}{|lcccccc|}
\hline & & \multicolumn{3}{c}{$\begin{array}{c}\text { Fraction } \\
\text { of Time } \\
\text { Working }\end{array}$} & $\begin{array}{c}\text { r } \\
\text { Income } \\
\text { Gini }\end{array}$ & $\begin{array}{c}\text { Percentage of } \\
\text { Retired Agents } \\
\text { at Floor Level }\end{array}$ \\
\hline US System & 2.91 & .396 & .314 & 6.4 & .40 & \\
Boskin & & & & & & \\
Proposal & & & & & & \\
$\underline{b}=.0 Y$ & 2.96 & .411 & .330 & 6.2 & .39 & 0.0 \\
$\underline{b}=.15 Y$ & 2.94 & .407 & .324 & 6.2 & .40 & 15.6 \\
$\underline{b}=.25 Y$ & 2.89 & .401 & .315 & 6.5 & .40 & 41.0 \\
$\underline{b}=.35 Y$ & 2.81 & .391 & .307 & 6.8 & .41 & 59.2 \\
\hline
\end{tabular}

Second. we observe that under the Boskin proposal increases in the floor benefit always reduce aggregate capital and labor inputs. The reduction in aggregate capital is related to the increase in the income tax rate needed to finance transfer benefits for an increasing percentage of agents whose retirement annuity income falls below the floor level. ${ }^{23}$ Notice that for $\underline{b}=.35 Y$

\footnotetext{
${ }^{23}$ For instance. transfers needed to finance $\underline{b}=0.35 Y$ are in the order of $1.3-1.4 \%$ of GDP in the no idiosyncratic case. This results in income tax rates going from $18.7 \%$ in the zero floor situation to $22.3 \%$ for $\underline{b}=0.35 Y$.
} 
this percentage is about $60 \%$ in the both the idiosyncratic shock and the no idiosyncratic shock case. One reason for the reduction in aggregate labor input is simply that when floor benefit levels are raised low ability agents reduce the fraction of time spent working (see section 4.2.2). This occurs as low ability agents who will receive the floor benefit with certainty get no marginal benefit for an additional unit of social security taxes paid.

Table 4: General Features - Idiosyncratic Shocks

\begin{tabular}{|c|c|c|c|c|c|c|}
\hline & $\mathrm{K} / \mathrm{Y}$ & L & $\begin{array}{l}\text { Fraction } \\
\text { of Time } \\
\text { Working }\end{array}$ & $\mathrm{r}$ & $\begin{array}{c}\text { Income } \\
\text { Gini }\end{array}$ & $\begin{array}{l}\text { Percentage of } \\
\text { Retired Agents } \\
\text { at Floor Level }\end{array}$ \\
\hline $\begin{array}{l}\text { US System } \\
\text { Boskin } \\
\text { Proposal }\end{array}$ & 3.06 & .413 & .312 & 5.8 & .43 & \\
\hline$\underline{b}=.0 Y$ & 3.11 & .434 & .329 & 5.6 & .43 & 0.0 \\
\hline$\underline{b}=.15 Y$ & 3.08 & .429 & .322 & 5.7 & .43 & 12.7 \\
\hline$\underline{b}=.25 Y$ & 3.02 & .421 & 312 & 6.0 & .44 & 39.1 \\
\hline$\underline{b}=.35 Y$ & 2.95 & .413 & .306 & 6.2 & .44 & 58.8 \\
\hline
\end{tabular}

It is important to point out that the model economies are able to approximate some distributional features of the US economy. In particular. Table 4 shows that under the US system the model economy is able to approximate the US income Gini coefficient estimated by Ryscavage (1995). ${ }^{24}$ For a discussion of the extent to which similar model economies can match features of the distribution of wealth and savings see Huggett (1996) and Huggett and Ventura (1996).

\subsection{Distributional Effects of Reform}

The analysis of distributional effects focuses first on the changes in welfare. and then on changes in the distribution of consumption and labor over the life cycle produced by versions of the Boskin proposal.

\footnotetext{
${ }^{24}$ The concept of income used is labor plus asset income before taxes, plus social security transfers. Using data from the Consumer Population Survey and an equivalent definition of income. Ryscavage (1995) reports that the income Gini coefficient averaged .43 for the period 1990- 1995.
} 


\subsubsection{Compensating Variations}

We analyze welfare effects by calculating compensating variations at birth for agents born with different ability levels. Our compensating variations list the negative of the percentage that consumption must be increased or decreased by each period over a lifetime to leave a given agent as well off in the Boskin proposal as in the US system. Thus. our measure is negative if an agent experiences a welfare loss under the Boskin proposal and is positive if an agent experiences a welfare gain.

Figure 3 shows welfare gains at different $\log$ ability levels at birth. An ability level of 1 is the lowest whereas an ability level of 21 is the highest. Recall from section 3.2 that these ability levels are evenly spaced on a $\log$ scale and vary from four standard deviations below the mean $\left(-4 \sigma_{y_{1}}\right)$ to four standard deviations above the mean $\left(4 \sigma_{y_{1}}\right)$. As log ability is normally distributed and centered at an ability level of 11 . the bulk of the agents in the economy have ability levels concentrated around an ability level of 11 . Figure 3(a)-(b) clearly shows that high ability agents are the winners and low ability agents are the losers under the Boskin proposal with a floor level of zero. Under a floor of zero. the magnitude of the welfare changes for agents with low and high ability levels is quite striking. High ability agents experience a gain ranging from a $10-15 \%$ increase in consumption whereas low ability agents experience a welfare loss worth a $15-35 \%$ decrease in consumption. In section 4.2.2 we will document the changes in the profiles of consumption and labor over the life cycle that generate the distributional effects in Figure 3 (a)-(b).

\section{[Figure 3 (a)-(b)-Boskin vs. L'S ]}

With higher settings of the floor benefit. low and high ability agents experience a welfare gain but agents with median ability levels still suffer a welfare loss. Thus. the distributional effects display the $\dot{C}^{-}$-shape shown in Figure 3 (a)-(b). It is interesting to try to develop some intuition for which features of the economy determine these distributional effects. The candidates are changes in redistribution. changes in distortions and changes in insurance as well as the general equilibrium effects on factor prices that these three effects bring about. Differences in factor prices are not responsible for much of the observed patterns. We have verified that when factor prices are held 
constant at their values under the LS system the results are almost indistinguishable from those in Figure 3 (a)-(b). This exercise could be thought of as a calculation of welfare changes using an open economy assumption.

We postulate that differences across equilibria in redistribution are quite important in explaining the patterns in Figure 3. Under the Boskin proposal with a zero floor. benefits are proportional to taxes paid. Thus, low ability agents lose both the redistribution coming from the concave old-age benefit schedule as well as from the common benefit coming from hospital and medical insurance under the US system. This accounts for the welfare loss of low ability agents and the welfare gains of high ability agents. At higher floor levels the income tax must be raised to pay for higher floor benefits. This reduces the welfare gains of the high ability agents who are unlikely to ever be at the floor benefit level. Low ability agents can experience a welfare gain as the higher floor level offsets any negative effects of the higher income taxes needed to pay for these floor benefits. Figure 3(a)-(b) indicates that median ability agents (e.g. ability level 11) do not gain from participating in any version of the Boskin proposal.

We now provide one possible aggregate measure of steady-state welfare gains to adopting the Boskin proposal in place of the US system. To do this we create a social welfare measure that is a weighted average of the utilities of different agent types at birth. where the weights are the fraction of the different agent types at birth ${ }^{25}$

Using this measure of welfare. compensating variations are calculated and presented in Table $j$ (a). One interpretation of this compensating variation is the percentage gain or loss (in terms of consumption each period) that an agent receives living under the Boskin proposal relative to living under the C'S system. given that the ability level at birth is uncertain. Table $j$ (a) shows that. despite important welfare gains for some agents shown in Figure 3. the aggregate welfare measure is never positive for the floor levels considered 26

\footnotetext{
${ }^{25} \mathrm{M}$ Iore formally: the welfare notion is $\sum_{z} p(z) V^{i}(0,0 . z .1)$, where $p(z)$ denotes the fraction of age 1 agents receiving shock $z$, and $i=$ \{US Svistem. Boskin proposal\}.

${ }^{26}$ One caveat is necessary to interpret properly the welfare gains in table 5. Comparisons of welfare gains in the idiosyncratic shock economy to the no idiosyncratic shock economy do not provide a measure of insurance possibilities in the Boskin proposal relative to the US system. One reason for this is because the variance of the ability shocks differs at birth in these two economies.
} 
Table 5 (a): Welfare Gains (\%)

\begin{tabular}{|l|c|c|}
\hline $\begin{array}{l}\text { Model } \\
\text { Economy }\end{array}$ & $\begin{array}{c}\text { No Idiosyncratic } \\
\text { Shocks }\end{array}$ & $\begin{array}{c}\text { Idiosyncratic } \\
\text { Shocks }\end{array}$ \\
\hline$\underline{b}=0.0$ & -3.5 & -2.4 \\
$\underline{b}=0.15 Y$ & -1.9 & -1.3 \\
$\underline{b}=0.25 Y$ & -0.9 & -0.3 \\
$\underline{b}=0.35 Y$ & -1.5 & -0.9 \\
\hline
\end{tabular}

Table 5 (b): Agents with Welfare Losses at Birth $(\%)$

\begin{tabular}{|l|c|c|}
\hline Model & $\begin{array}{c}\text { No Idiosyncratic } \\
\text { Economy }\end{array}$ & $\begin{array}{c}\text { Idiosyncratic } \\
\text { Shocks }\end{array}$ \\
\hline$\underline{b}=0.0$ & 57.9 & 72.5 \\
$\underline{b}=0.15 Y$ & 72.5 & 72.5 \\
$\underline{b}=0.25 Y$ & 80.5 & 72.1 \\
$\underline{b}=0.35 Y$ & 80.5 & 88.3 \\
\hline
\end{tabular}

One plausible conjecture is that the welfare results in Figure 3 and Table 5 are both due to a lack of redistributional flexibility towards agents with median earnings ability built into the Boskin proposal and not because labor distortions are more onerous under the Boskin proposal. In particular. in adopting the Boskin proposal median ability agents lose the common hospital and medical transfer built into the LS system. We now examine if changing only the old-age component of social security: while maintaining the hospital and medical transfers in both systems. produce qualitatively and quantitativey different results.

The results of this exercise are presented in Figure 4 and Table 6. ${ }^{27}$ Qualitatively: the compensating variations in Figure 4 are similar to those reported previously: However. the magnitude of welfare gains and losses are different. We see that (i) the striking welfare losses of low ability agents at the lowest level of the floor benefit are no longer present and (ii) the large welfare

\footnotetext{
${ }^{2 \pi}$ To carry out the calculations. the parroll tax in the US Srstem. is split in two parts $\left(\theta_{1}+\theta_{2}=\theta\right)$. The first part is obtained as the one that finances the common transfer $b$ in the US System. Once the taxes are found. they are kept constant in the calculations for the Boskin proposal. Notice that since $\theta_{1}$ finances the common transfer. $\theta_{2}$ is the rate at which labor earnings accumulate in the social security scheme. Benefits at retirement are then equal to $\max \left\{\underline{b}, b+b\left(a_{2}, j j\right\}\right.$.
} 
gains for high ability agents are reduced. It is then clear that the presence of the common transfer $b$ in the Boskin proposal generates a less unequal distribution of welfare gains at birth.

[Figure 4 (a)-(b)- Boskin vs. US - Medical and Hospital Benefits Held Constant]

Table 6 (a): Welfare Gains (\%)

\begin{tabular}{|l|c|c|}
\hline Model & $\begin{array}{c}\text { No Idiosyncratic } \\
\text { Economy }\end{array}$ & $\begin{array}{c}\text { Idiosyncratic } \\
\text { Shocks }\end{array}$ \\
\hline$\underline{b}=0.0$ & -1.3 & -0.80 \\
$\underline{b}=0.15 Y$ & -1.3 & -0.81 \\
$\underline{b}=0.25 Y$ & -0.3 & 0.16 \\
$\underline{b}=0.35 Y$ & -0.4 & -0.15 \\
\hline
\end{tabular}

Table 6 (b): Agents with Welfare Losses at Birth (\%)

\begin{tabular}{|l|c|c|}
\hline $\begin{array}{l}\text { Model } \\
\text { Economy }\end{array}$ & $\begin{array}{c}\text { No Idiosyncratic } \\
\text { Shocks }\end{array}$ & $\begin{array}{c}\text { Idiosyncratic } \\
\text { Shocks }\end{array}$ \\
\hline$\underline{b}=0.0$ & 72.5 & 72.6 \\
$\underline{b}=0.15 Y$ & 72.6 & 72.6 \\
$\underline{b}=0.25 Y$ & 76.1 & 64.5 \\
$\underline{b}=0.35 Y$ & 69.0 & 69.0 \\
\hline
\end{tabular}

The result that emerges from tables $6-\mathrm{A}$ and $6-\mathrm{B}$ is that keeping the common transfer of medical and hospital benefits in the Boskin proposal reduces significantly the aggregate welfare losses shown previously. In just one particular situation (the case of idiosyncratic shocks and $\underline{b}=0.25 Y$ ) the Boskin Proposal dominates the LS System in terms of the aggregate welfare measure even though not in terms of the percentage of agents who are better off after birth.

\subsubsection{Consumption and Labor Profiles}

We now document how the cross-sectional profiles of consumption and labor differ under the US system and under the Boskin proposal. These profiles are graphed in in Figures 5 (a)-(c) and 6 (a)-(c) for the case of no idiosyncratic uncertainty. 
[Figure $5(\mathrm{a})-(\mathrm{c})$ - distribution of labor hours]

In Figure 5(a) agents allocate on average $35-40 \%$ of their time to market work when young under the US system. This percentage declines sharply as agents approach age 65 . The patterns we calculate for the ${ }^{-}$'S system are quite similar to those calculated by Rios-Rull (1996) in a related model that abstracted. among other things, from the structure of the IS social security system. Rios-Rull demonstrated that the average fraction of time allocated to market work at different stages of the life cycle in his model roughly approximated the average labor hour pattern he calculated using US data from the Current Population Survev. He argued that the pattern in his model was determined by the variation in the efficiency of labor time over the life cycle. As we follow Rios-Rull in using the efficiency profile calculated by Hansen (1993), previously presented in Figure 1, and in using similar magnitudes for the elasticity of intertemporal substitution, the patterns in our model with social security and in his model without social security turn out to be similar.

A notable feature of figure $5(a)$ is that there is a significant difference in the cross-sectional pattern of labor under the Boskin proposal with a zero floor as compared to the L'S system. The average fraction of time worked is more than $5 \%$ higher early in life under the Boskin proposal as compared to under the US system. A natural conjecture is that this is largely due to differences in work incentives under the two systems. Under the Boskin proposal with a zero floor. benefits are proportional to the accumulated future value of taxes paid up to the time of retirement. whereas under the US system benefits depend on average indexed earnings, not the timing of earnings. Thus. agents under the Boskin proposal have a higher return on a unit of social security tax payments early in life as compared to a unit of tax payments later in life as. these payments effectively pay interest (see section 2.2.2).

Figure 5 (b) graphs the distribution of labor hours across ability levels over the life cycle under the Boskin proposal with a floor benefit equal to $35 \%$ of average income in the economy: Figure $\bar{j}(\mathrm{~b})$ demonstrates that with a high benefit floor level $(\underline{b}=0.35 Y)$. even in the absence of idiosyncratic uncertainty, agents with high ability work more than their low ability counterparts. The reasons for this phenomenon are as follows. When the floor 
level is increased. the marginal returns to social security tax payments differ across agents. For high ability agents the logic described above still applies as these agents will be above the floor level with certainty. However, agents with low ability levels will receive an annuity benefit that puts them below the floor level with certainty. Thus. they will receive a zero marginal return on all social security tax payments. This reduces labor supply over the life cycle for these agents, as can be seen in Figures 5 (b).

The negative effects of higher floor benefit levels on labor hours supplied by low ability agents can be further confirmed in Figure 5 (c). This figure graphs. for a relatively low ability level, the distribution of of labor hours under the Boskin proposal with the lowest and the highest benefit floors (zero and $35 \%$ of arerage income respectively). We observe here that low ability agents reduce labor hours significantly, relative to the zero floor situation.

Figures 6 (a)-(c) graph the cross-section patterns of consumption. Several features are worth noting here. First, low ability agents experience an upward jump in consumption at the retirement age in the cases of the US System and Boskin proposal with $\underline{b}=0.35 Y$. This is explained by the presence of the borrowing constraint, which prevents these agents to borrow early in life in order to smooth the quite important increase in income produced by the social security benefit (recall that benefits are not proportional to contributions). Second. notice that the cross-section pattern of consumption for low ability agents differs dramatically betweeen the US System and the Boskin scheme with a zero benefit floor. as with the latter (i) social security transfers are proportional to taxes paid. and (ii) the common transfer is lost. These features dictate that the jump in consumption at age 65 mentioned above is not observed in the version of the Boskin plan with a zero retirement floor. as figure 6 (b) demonstrates. The fall in consumption after the retirement age relative to the L'S System case. in conjunction with the lower amount of leisure enjoyed by low ability agents under a zero floor. accounts for the quite dramatic welfare losses for these agents documented in section 4.2.1.

[Figure 6(a)-(c) - distribution of consumption] 


\section{Conclusion}

This paper has focused on the potential distributional effects of replacing the current I'S social security system with a two-tier system that we refer to as the Boskin proposal. This is a difficult question to answer for a number of reasons of which we will mention four. First, social security systems affect consumers by redistributing income, distorting the labor-leisure decision and by changing insurance possibilities when markets are incomplete. Thus, distributional effects are not well summarized by a calculation of the present value of taxes paid and benefits received. Second, a full analysis of distributional effects requires an analysis during transition as well as after the transition is over. Third. as the current ['S system is not in a situation in which current tax rates and benefit formulas appear to be financially feasible over time. a deeper analysis requires the consideration of time varying tax rates and benefit formulas as well as projected changes in demographics. Fourth, a meaningful quantitative analysis of distributional effects requires a model that at a minimum can reproduce some of the distributional facts of the US economy.

Our strategy for analyzing distributional effects is two-fold. First. we have chosen to simplify the problem by abstracting from transition as well as from time variation in demographics and social security tax rates and benefit formulas. These abstraction allow us to extract cleanly a number of key insights that would also be present but in a more complicated fashion without these abstractions. Second. we adopt a particular version of the life-cycle model that is calibrated to match a number of distributional and aggregate features of the L'S economy as our laboratory for evaluating distributional effects.

The main findings of our analysis relate to changes in the allocation of labor over the life cycle as well as to who are the winners and the losers of reform. As the basic logic of why average labor hours increase early in the life cycle under the Boskin proposal and why the labor of low ability agents decreases with incerases in floor benefits are summarized in the introduction. we will focus on our results for who are the winners and losers of reform. Our findings along this dimension are that households who are either above or below median earnings ability levels at birth have the potential to gain substantially from implementing various versions of the Boskin proposal. Unfortunately: there is no free lunch for all concerned as households with 
median earnings ability never gain from any version of the Boskin proposal. This finding is not sensitive to abstracting from idiosyncratic labor income shocks. is not sensitive to whether one assumes that factor prices are or are not affected by changes in social security systems and is not sensitive to mantaining a common health component of benefits in both systems.

We close the paper with a question: Why are two-tier social security systems being adopted in several countries when we do not find strong reasons for adopting them for the 'S economy? We briefly list three possible answers that future research should address. First, fully-funded financing makes a big difference. The reason is simply that. unlike the pay-as-you-go systems studied in this paper. the impact on aggregate quantities and factor prices is expected to be quite significant. Such a big difference would arise. nevertheless. when comparing steady states. It should be pointed out that it is by no means clear, a priori. that a majority of the population at the time of the reform will prefer the new social security scheme. Second, private management of social security funds in the countries adopting them entails better risk-return characteristics as there is less corruption in handling the funds and more predictability in determining eventual retirement benefits. Finally, the generic two-tier reforms studied in this paper redistribute away from median ability agents. More popular systems may screw high ability agents so as to benefit agents with median abilities. 


\section{REFERENCES}

H. A.ARON (1982). " Economic Effects of Social Security:" Brookings Institution: Washington DC.

A. Auerbach tivd L. Kotlikoff (1987). " Drnamic Fiscal Policy:" Cambridge University Press.

M. Boskin (1986), "Too Many Promises: The Uncertain Future of Social Security;:" Dow Jones-Irwin.

L. Cerda and G. Grandolini (1997): “ Mexico: La reforma al Sistema de Pensiones." Gaceta de Economia 4. 63-105.

G. Ghez AND G. Becker (1975), " The Allocation of Time and Goods Over the Life C. .cle." New York: National Bureau of Economic Research.

G. HANSEN (1993). "The C'rclical and Secular Behavior of the Labor Input: Comparing Efficiency Units and Hours Worked." Journal of Applied Econometrics 8, 71-80.

H. Huang, S. IMrohoroglu and T. SARgent (1997), :" Two Computational Experiments to Fund Social Security;" Macroeconomic Dynamics 1. 1.

G. HUBBARD AND K. JUDD (1987), " Social Security and Individual Velfare: Precautionary Saving, Liquidity Constraints and the Payroll Tax." American Economic Review 77, 630-46.

G. Hubbard J. Skinner and S. Zeldes (1995). * Precautionary Savings and Social Insurance." Journal of Political Economy 103. 2; 360-399.

M. HuggetT (1996), "Wealth Distribution in Life-Crcle Economies." Journal of Monetary Economics 38, 469-494.

M. HUggetT AND G. Ventura (1997), "Linderstanding Why High Income Households Save More Than Low Income Households." "iniversity of Illinois: mimeo.

M. HURd AND J. SHOVEN (1983). " The Distributional Impact of Social Security:" NBER Working Paper 1155.

M. HURd (1989), “Mortality Risk and Bequests." Econometrica 57. Ti79-813.

A. IMrohorogll: S. IMrohoroglu and D. JoInes (1995). "A Life Cycle Analysis of Social Security:" Economic Theory 6. 83-114.

F. JLSTER AND F. STAFFord (1991). " The Allocation of Time: Empirical Findings, Behavioral Models and Problems of Measurement." Journal of Economic Literature 29. $\quad 471-522$.

L. Kotlikoff (1996). " Privatization of Social Security": How it Works and Why it Matters." Tax Policy and the Economy 10. 1-32.

E. PrescotT (1986). "Theory Ahead of Business Cicle Measurement." Federal Reserve Bank of Minneapolis Quarterly Review. 9-22. 
IV. Press. Telkolsky, S.. Vetterling. W. and Fl.annery. B. (1994), “ Numerical Recipes in Fortran: The Art of Scientific Computing," Cambridge University Press. 2nd. ed.

J.V. Rios-Rull (1996), " Life-Cycle Economies and Aggregate Fluctuations." Review of Economic Studies 63. $\quad 465-89$.

P. Ryscavage (1994), " Gender Related Shifts in the Distribution of Wages:" . Ionthly Labor Reriew . 3-16.

P. RYSCAVAGE (1995), " A Surge in Growing Income Inequality?." Monthly Labor Review. 51-61.

A. SHORrocks (1980), "Income Stability in the United States.:" in The Statics and Dynamics of Income, ed. N. Klevmarken and J. Lrbeck: Tieto Ltd.

E. Steurle AND J. BakiJA (1994). " Retooling Social Security for the 21st Century," Washington. DC: The Urban Institute Press.

N. STOKey' AND S. Rebelo (1995), "Growth Effects of Flat-Rate Taxes." Journal of Political Economy 103, j19-550.

L. ThompSON (1983), " The Social Security Reform Debate," Journal of Economic Literature 21. 1425-1467.

WORLD BANK (1994), " Averting the Old Age Crisis: Policies to Protect the Old and Promote Growth." Oxford; Oxford University Press. 


\section{Appendix 1}

Equilibria to the model of the LS System are computed using the following algorithm.

1. Guess values for capital. labor. transfers and tax rates: $K . L . T, \tau$ and $\theta$.

2. Factor prices are then $w=A F_{2}(K, L)$ and $r=A F_{1}(K . L)-\delta$.

3. Calculate optimal decision rules: $a(x, j), l(x, j)$ and $c(x, j)$.

4. Calculate values of $K . L . T . \tau$ and $\theta$ that are implied by the optimal decision rules in step 3 and the budget constraints governing social security and government consumption.

5. If the guessed values from step 1 equal the implied values in step 4 . then this is a steady state equilibrium. Otherwise. update the guess in step 1 and repeat these steps.

We now describe how to carry out steps 3 and 4 . In step 3 we put a grid on the state space $X$. We then start in the last period $N$ of an agent's life and solve for the control variables $y$ for each grid point in the state space $X$, setting $V(x, N+1)=0$. Given the maximizing values of controls $y$ on gridpoints, we then can determine values for the value function $V(x, N)$ on gridpoints. We use linear interpolations to get the period $N$ values of the value function and decision rules off of these gridpoints. This procedure can then be repeated to solve for value functions and decision rules for all earlier periods.

We now discuss how we solve the maximization problem each period at each grid point. We employ the following procedure which does not restrict control variables to lie on a grid:

1. For each state $x$. we obtain the best next period asset by first bracketing the optimum searching over asset gridpoints. Once an interval in the asset space containing the optimum has been found. the asset decision rule is computed using a golden search procedure. ${ }^{28}$. Notice that associated with every trial of $a^{\prime}$. either in the bracketing stage or in the golden search stage, there is a corresponding intertemporal labor decision. which we calculate by searching over the interval $[0.1 !$.

2. We put a grid of 101.4 and 21 points on values of $\left(a, \bar{e}_{,} z\right)$. The gridpoints on $\bar{e}$ correspond to zero. the two 'bend points' of the social security benefit schedule. a point consistent with the maximum social security benefits. The

\footnotetext{
${ }^{28}$ See Press er. al (1994) for details.
} 
spacing of the shocks was discussed previously. The spacing of points on the asset grid increases with asset levels. ${ }^{29}$

To calculate values of the variables in step 4 we simulate time paths of consumption. asset holdings, labor and social security transfers for a large number of agents. The sample is constructed using the Markov process followed by the idiosyncratic shocks to labor productivity, together with the probability distribution that determines shocks at birth. We then add up asset holdings and labor in efficiency units to calculate aggregate capital and labor inputs, and all the relevant aggregates. In these calculations we simulate 20.000 agents per cohort. In doing so. decision rules off gridpoints are obtained by interpolating decision rules on gridpoints. Simulations using larger numbers of agents change neither the values of these aggregates. nor the distributional properties of the model economies considered.

When we calculate equilibria under the Boskin Proposal. we again follow steps 1-5. The only changes are that we iterate on $(K, L, T, \tau)$ and the proportionality factor determining benefits in the Boskin proposal. The social security tax rate $\theta$ and the path of government consumption are set equal to those values obtained under the US System. To implement this procedure we put a grid of $(101,40,21)$ points on $\left(a_{1}, a_{2}, z\right)$. The spacing of the gridpoints on both $\left(a_{1}, a_{2}\right)$ is determined by the spacing used on $a_{1}$ previously.

\footnotetext{
${ }^{29}$ More specifically: asset gridpoints are placed according to $a_{1}=0 . a_{k}=b k^{2.35} . k=$ 2....101. The parameter $b=: \bar{a} / 101^{2.35}$ ). where $\bar{a}$ is an upper bound imposed on the asset space.
} 
Figure 1

\section{Wage Profile \\ Source: Hansen (1993)}

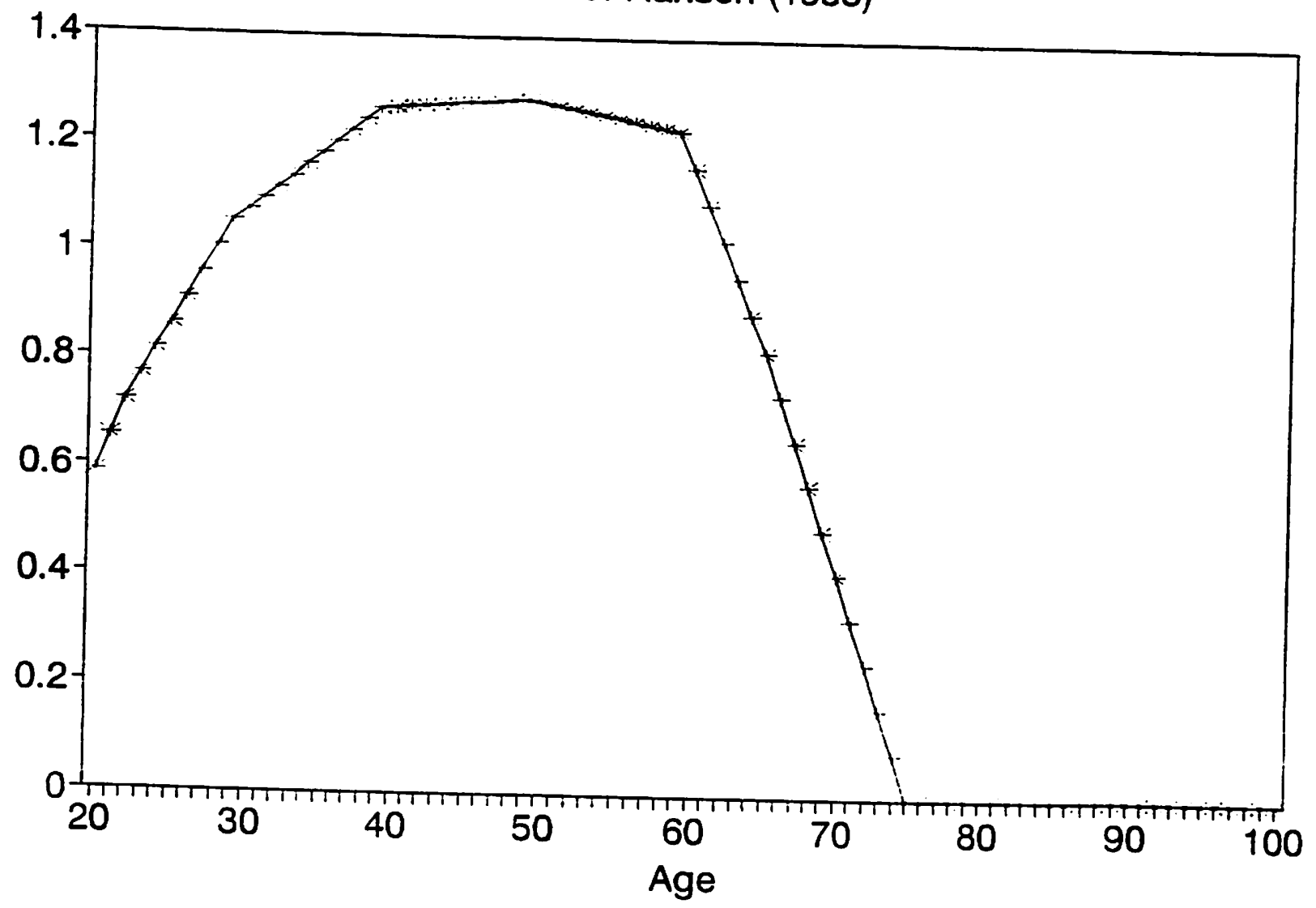




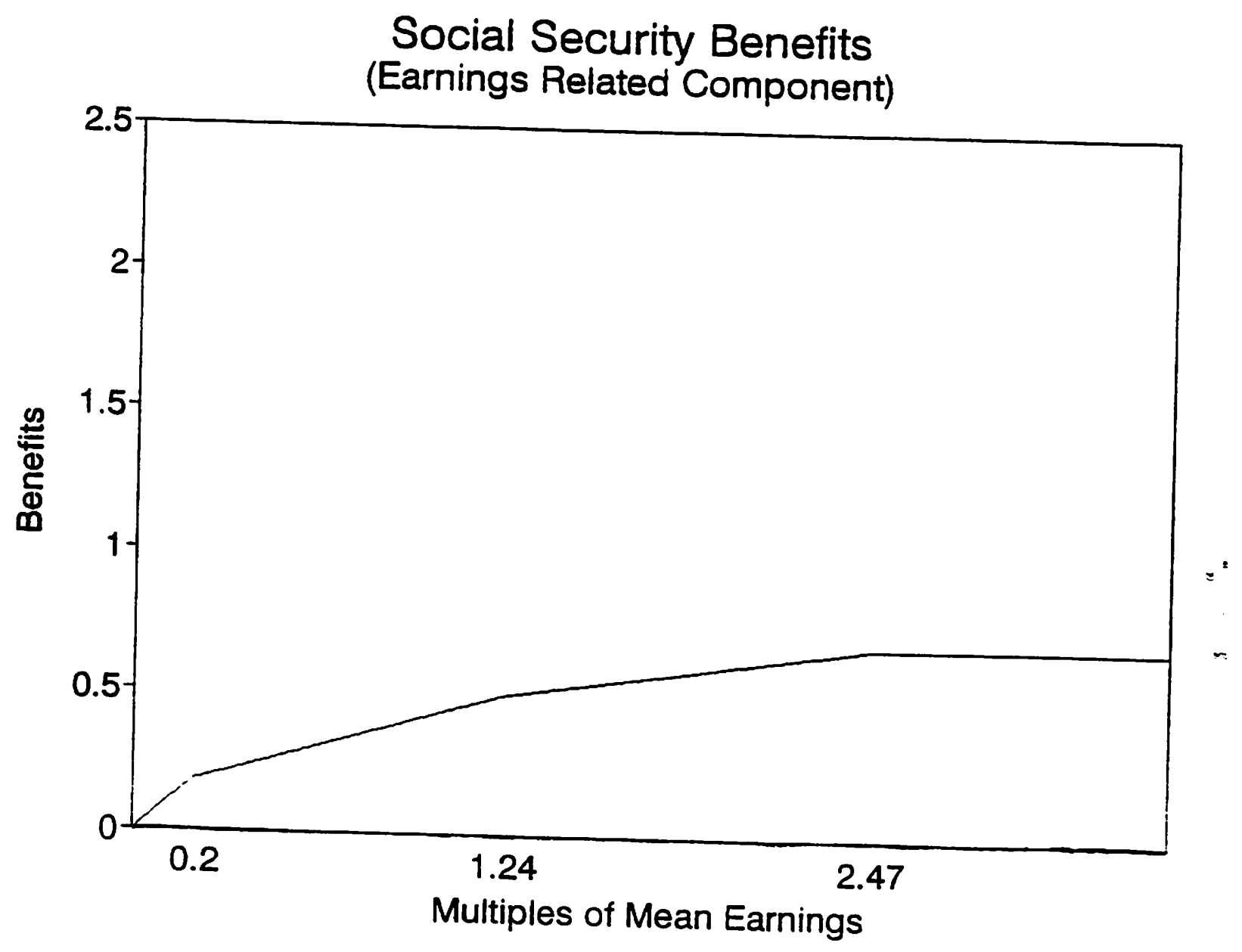




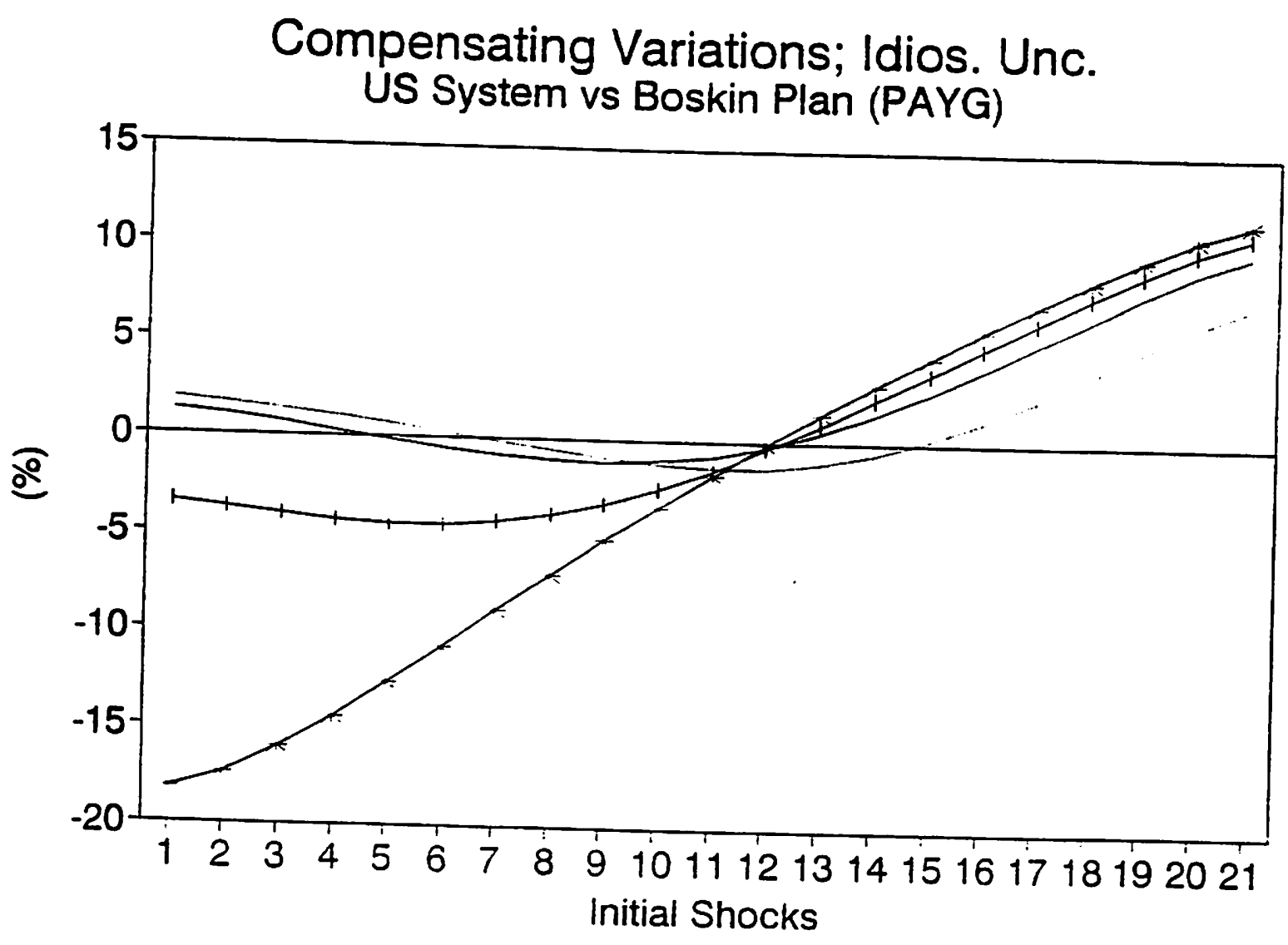

Floor $=0.0 \times Y-$ Floor $=0.15 \times Y-$ Floor $=0.25 \times Y-$ Floor $=0.35 \times Y$ 


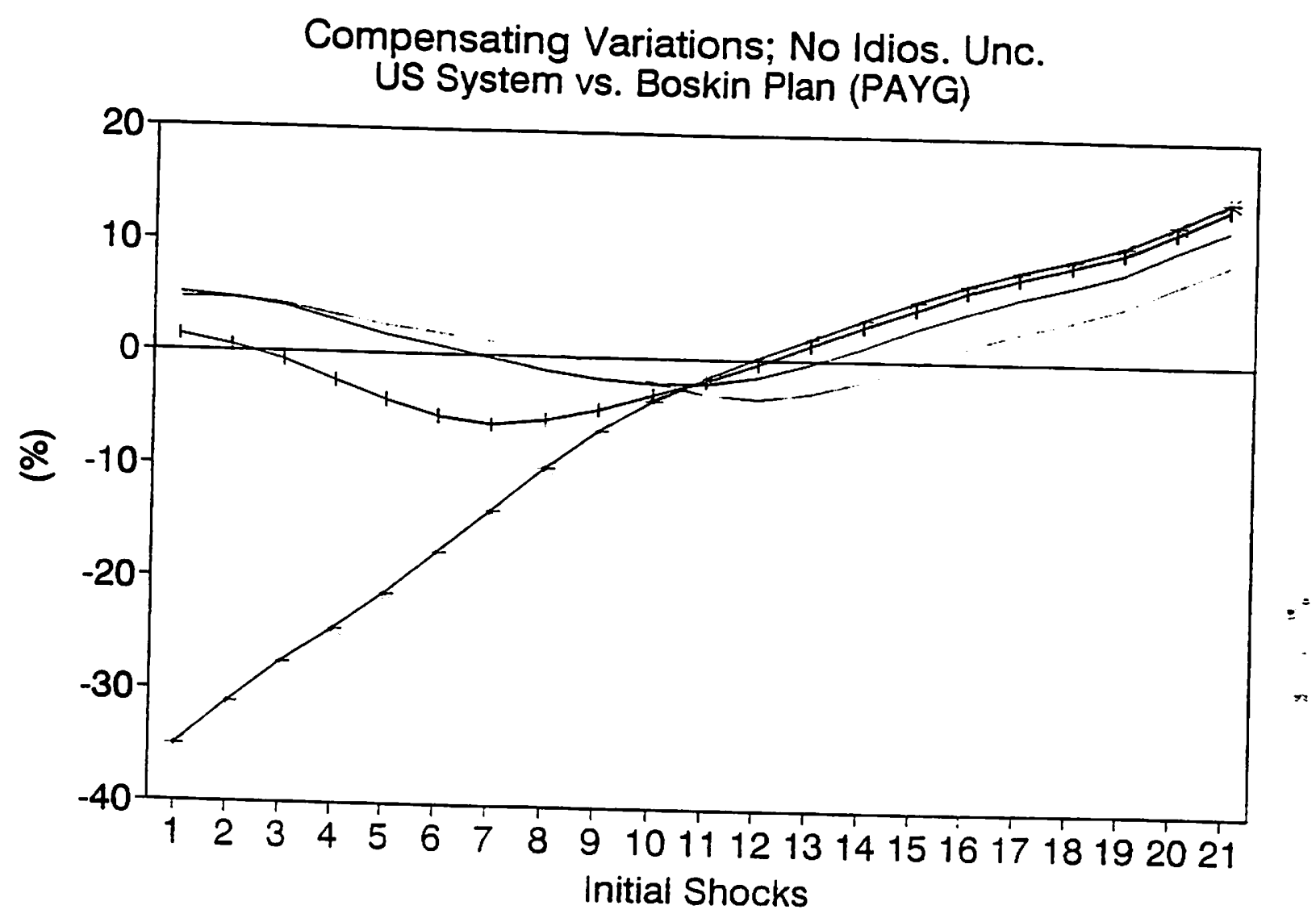

$$
\text { Floor }=0.0 \times Y \multimap \text { Floor }=0.15 \times Y-\text { Floor }=0.25 \times Y-\text { Floor }=0.35 \times Y
$$




\section{Compensating Variations (Idios. Unc.)} US System vs. Boskin (w/ Medical Ben.)

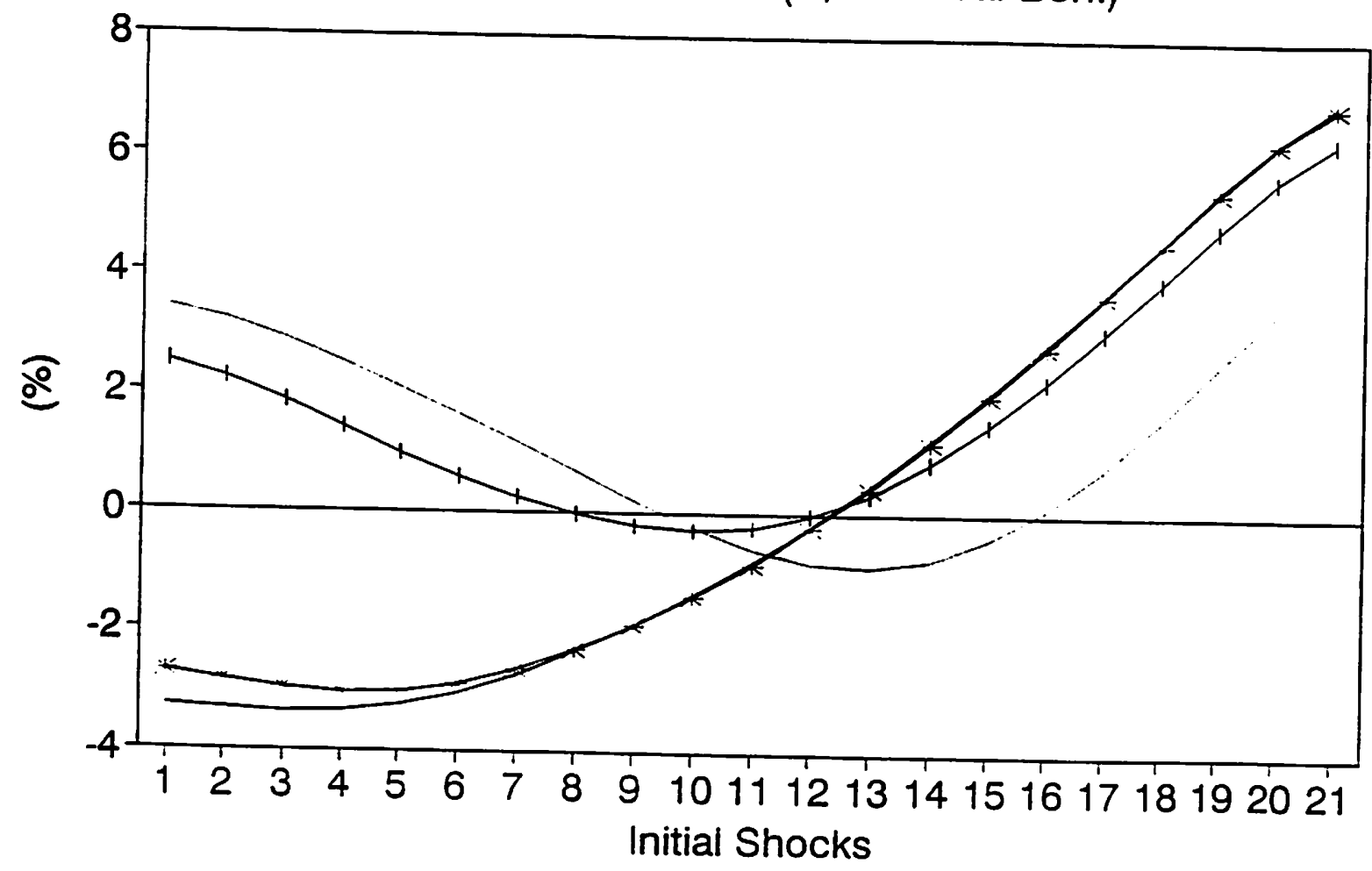


FIGURE $4-B$

Compensating Variations (No Id. Unc.)

US System vs. Boskin (w/ Med. Benefits)

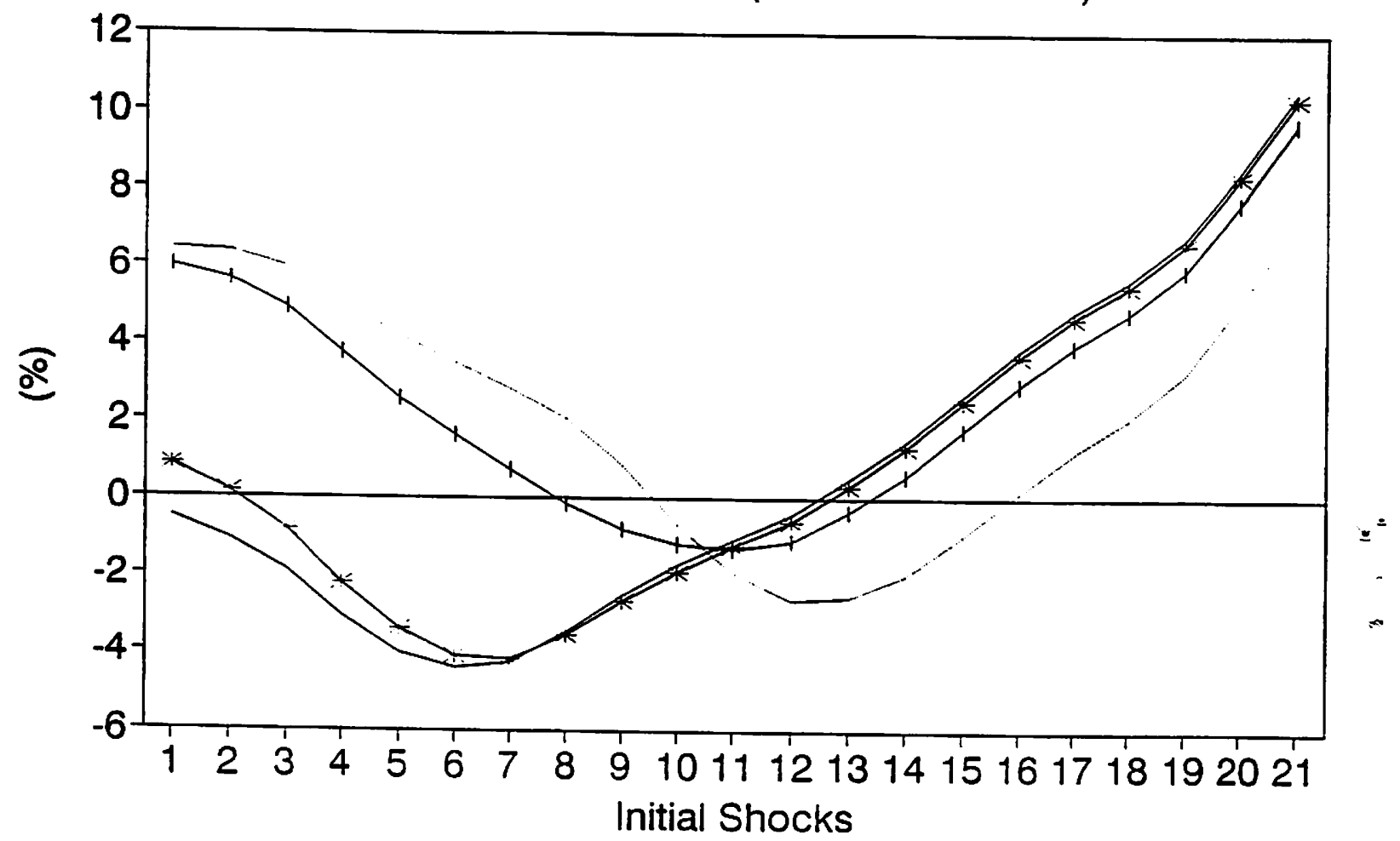


FIGURE 5-A

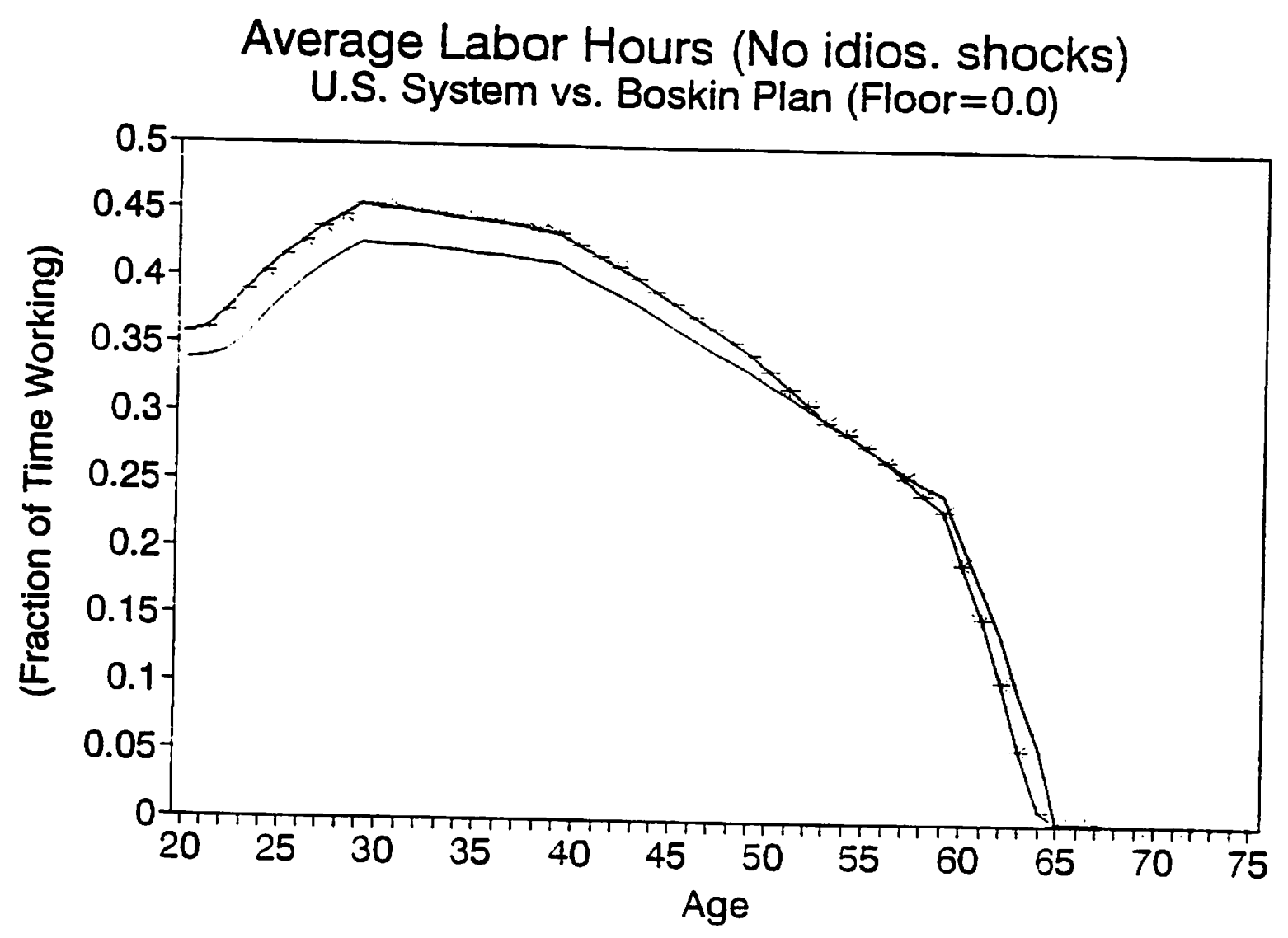

U.S. System - Boskin Plan 
FIGURE 5-B

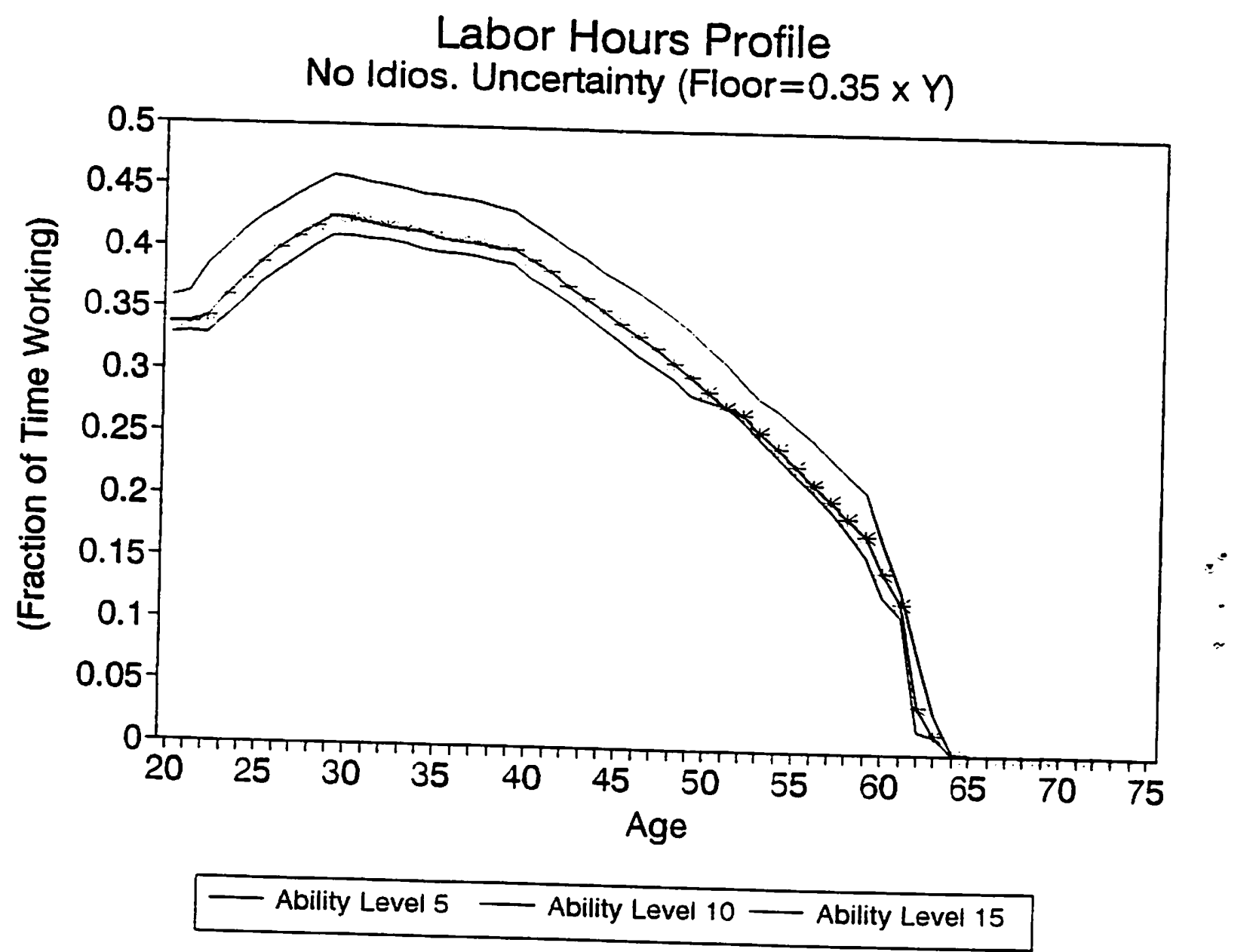


ficure 5-i

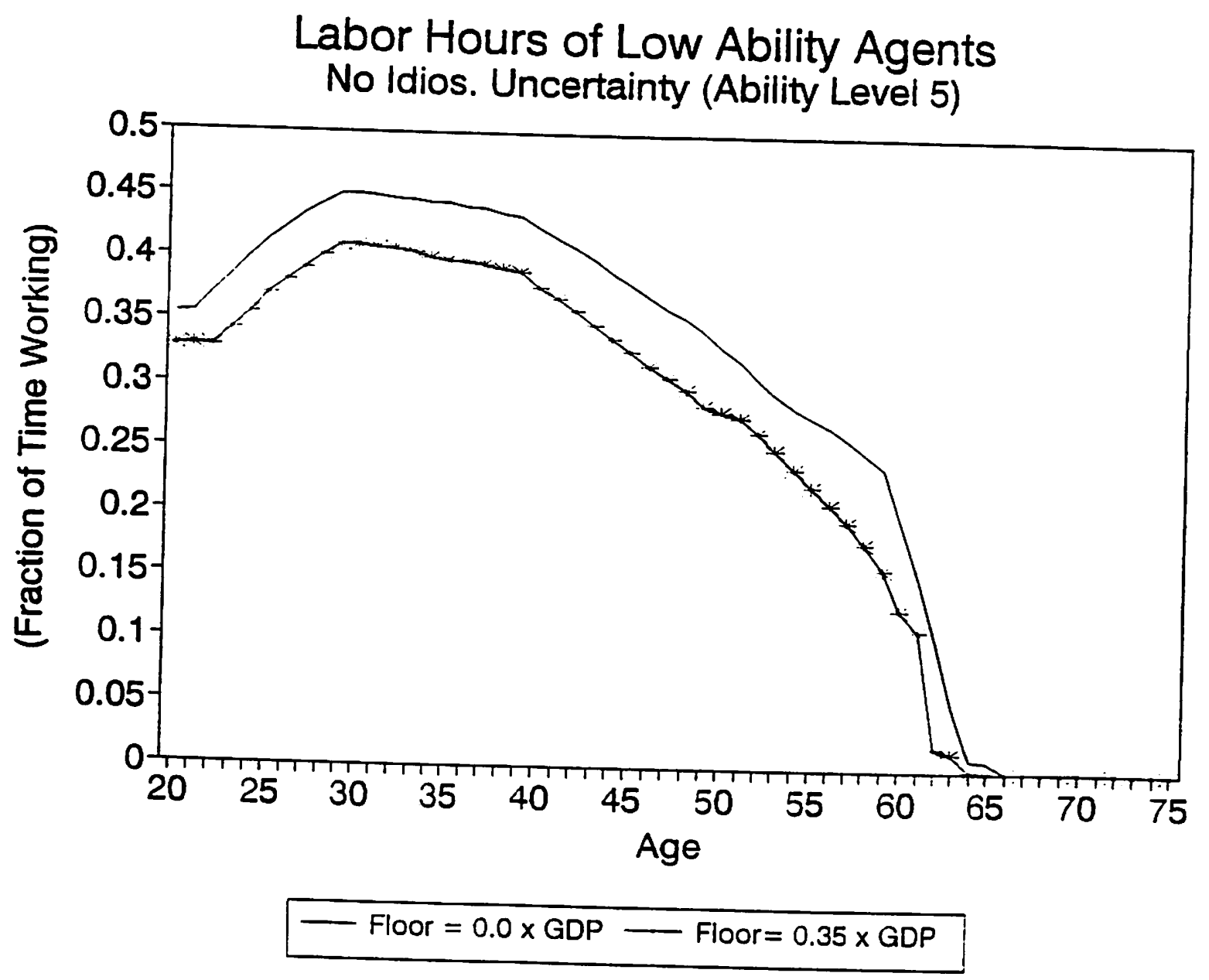


FicuRe 6 -A

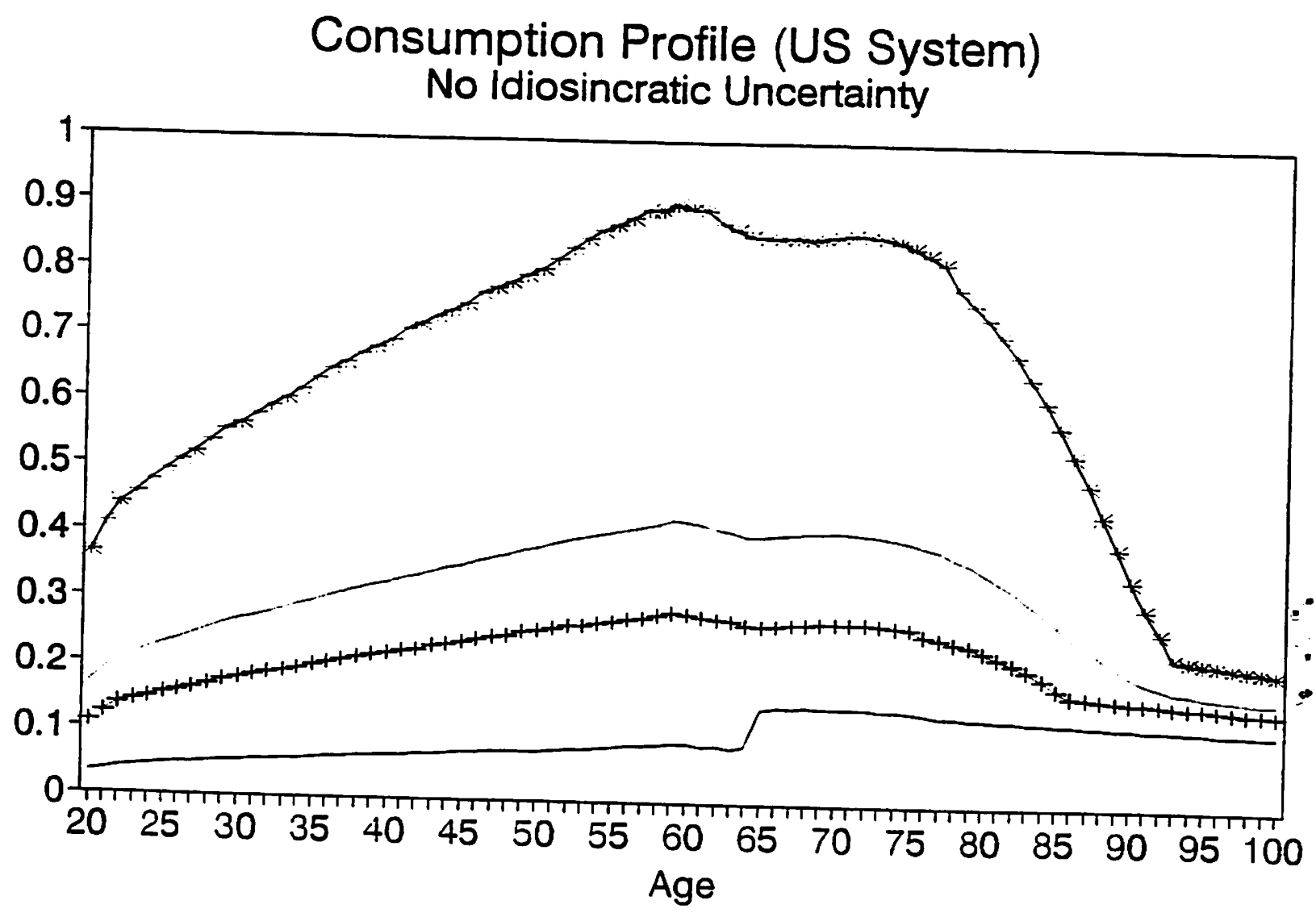


Ficure 6-B

\section{Consumption Profile (Boskin Scheme)}

Zero Floor; No Idios. Uncertainty

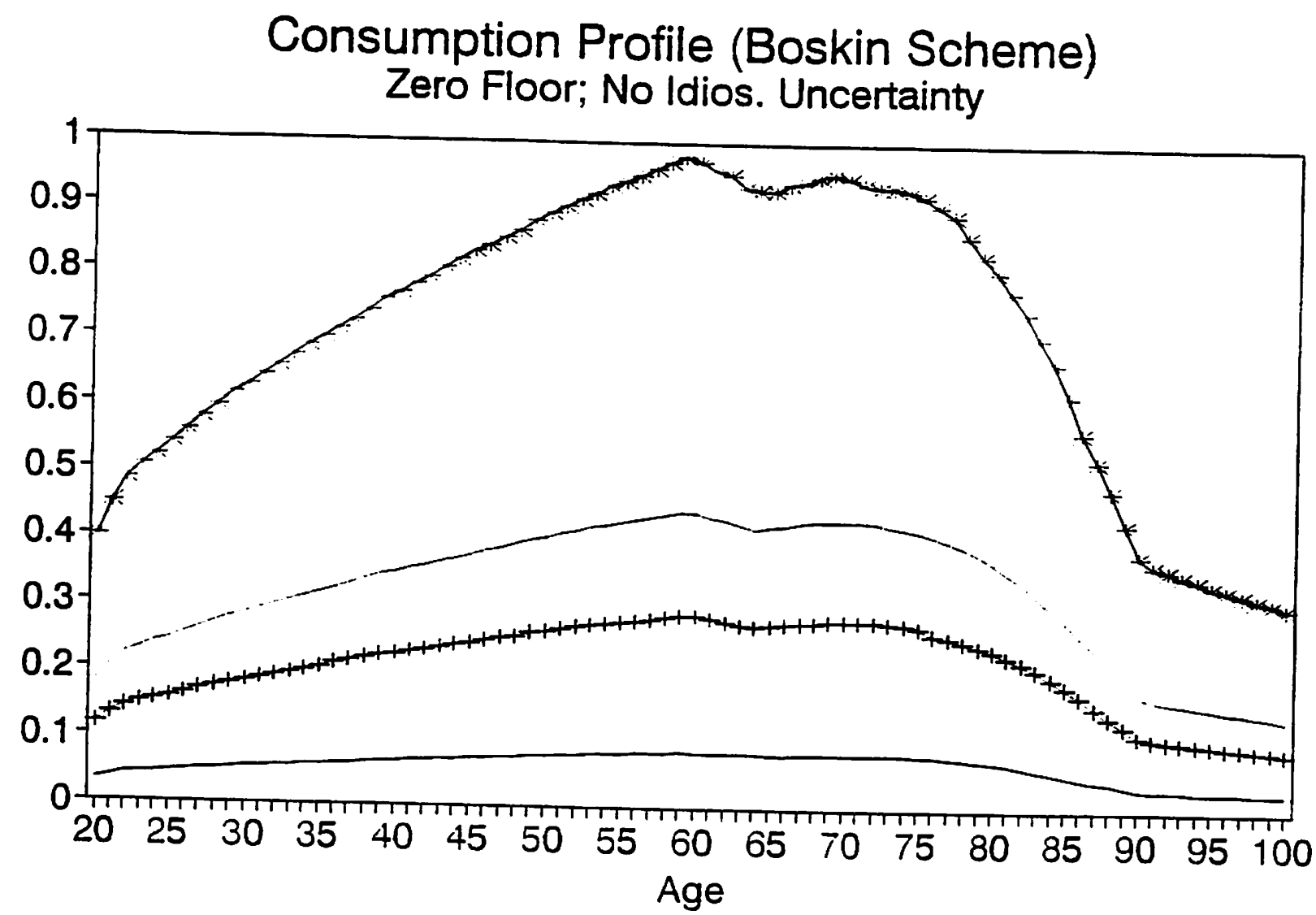




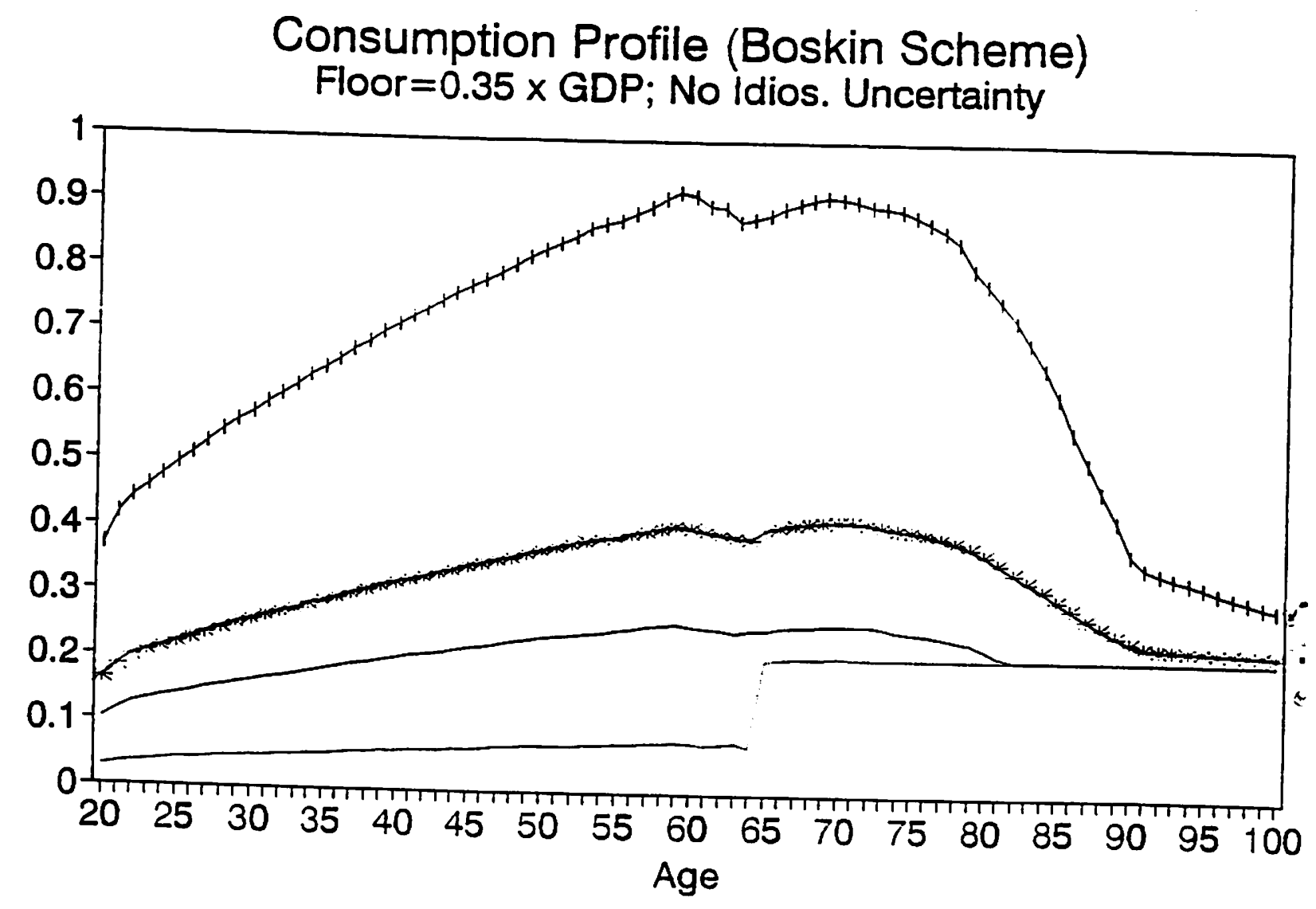

